\author{
W. Li, D. Li, X. Zhang, J. Cao \\ School of Electrical Engineering, Beijing Jiaotong University
}

\title{
STATUS AND RESEARCH PROGRESS OF THE LINEAR RAIL TRANSIT SYSTEM IN CHINA
}

\author{
Дата поступления 19.05.2015 \\ Решение о публикации 14.06.2015 \\ Дата публикации 28.03.2016
}

\begin{abstract}
The linear rail transit system (LRTS) has the advantages such as high performance, low construction cost, easy maintenance, friendly with the environment, the researchers all over the world therefore has focused their interests on the LRTS. Despite its late start, China is marking a rapid progress on the study of the linear rail transit system. The LRTS in China can be divided into two types: maglev train system and the linear metro system. This article will revolve around the two aspects above to address the develop status and the newly research progress of the LRST in China. Meanwhile, the article also presents the research progress of the high-temperature superconducting (HTS) linear motors used for LRTS.
\end{abstract}

Key words : Rail transit, maglev train, linear metro, HTS linear motor, research progress

\section{INTRODUCTION}

Linear motor can provide the linear thrust independent from any transmissions. Characterized by the advantages such as simple structures, high reliability, long service life and easy maintenance; the linear motor has wide prospects in the applications such as rail transit, electromagnetic launchers, servo system, etc., [1-4]. According to the structural from, the linear motor can be divided into two parts: the tubular linear motor and the flat linear motor. Due to the symmetrical structure, the normal forces of the tubular linear motor is counteracting with each other, thus the tubular linear motor is not influenced by the normal force. Therefore, it is widely utilized in the servo system and the linear actuators $[2,5,6]$. However, the flat linear motor is characterized by the simple structure and low construction cost. So the flat linear motors are applied to the applications such as rail transit and electromagnetic launchers [7-9].

The LRTS is propelled by the linear motor and guided by the wheel/rail system or the electromagnetic guidance system. As early as 1905, the scholars 
had advised to propel the trains by using the linear motor. Since that, the researches of the applications of linear motor to rail transit have been addressed in many countries such as Germany, Japan, the United Kingdom, Soviet Union, America, Canada, French, Korea, Switzerland, and China, and gotten rapid and very important progress. Up to now, there are more than 20 lines have been launched into commercial operation [10-12].

Despite its late start, China is marking a rapid progress on the research of the LRTS. Southwest Jiaotong University constructed the first maglev trains in 1994, and then the man-load test is conducted in the test facilities. The test facilities have 4 seats. It is $4 \mathrm{~T}$ weight. During the test operation, the levitated height is $20 \mathrm{~mm}$, and the operation speed is $30 \mathrm{~km} / \mathrm{h}$ [13-21]. In 2002, cooperated with Germany, China constructed the world's first commercial maglev railway demonstration line in Shanghai, the total length of the line is $29.86 \mathrm{~km}$, and the operation speed is $430 \mathrm{~km} / \mathrm{h}$. The China's first linear metro-Guangzhou metro line 4 was constructed in 2005 by China South Locomotive and Rolling Stock (CSR) and Kawasaki Heavy Industries (KHI). The whole line is $43.65 \mathrm{~km}$, maximum operation speed is $90 \mathrm{~km} / \mathrm{h}$, and the maximum climb capability is up to $70 \%$. After that, China constructed the Guangzhou subway line 5 and Airport Beijing City, etc., by itself.

During the operation of the linear rail transit system, the air gap between the primary of the motor installed in the vehicles and the secondary flatted along the rails will changes because of the installation accuracy, shake of the components of the machine, variations of the loads and the road conditions. To assure the safe and stable operation, the air gap of the linear motor is generally designed with a range from $10 \mathrm{~mm}$ to $100 \mathrm{~mm}[10,22,23]$. As we all know that the air gap flux density is decreased quickly with the air gap increasing. Furthermore, the end effect will also affect the flux density. Thus, the linear motor has lower efficiency and power factor than the rotation motors.

High-temperature superconducting (HTS) materials can transport current with low losses. Therefore, the machine developed by HTS materials has higher efficiency than the machine developed by conventional wires. Besides the high efficiency, the machine has other advantages such as small volume, less weight. In addition, the cooling medium is liquid nitrogen; the cost is also cut down. So the research on HTS linear motor has attracted wide attentions of the scholars all over the world. Japan is the first country who studies the applications of HTS technology to LRTS. In 1999, the researchers in Waseda University developed a single-sided HTS linear appliance integrated the levitated component and the propelled component. The levitated component is composed of 4 HTS bulks and permanent magnet rails, whereas the propelled component is composed of a zero field HTS bulk and the three-phase copper windings flatted along the tracks [24]. In 2002, the team developed a double-sided HTS linear motor, and 
analyzed the performances of the machine by finite element method [25-27]. The researchers in Kyushu University developed a double-sided HTS linear synchronous motor for elevator. The motor is 4 poles. The stator is developed by conventional copper wires and the rotor is constructed with HTS bulks [28-30]. In 2005, the same team in Kyushu University developed a new HTS reluctance motor and the thrust of the motor was optimized [31]. In 2004, Gorazd Stumberger developed a HTS linear synchronous motor used for electromagnetic launcher system. The magnets of the motor are made of HTS bulks. The scholars in Seoul National University developed an HTS linear synchronous motor in 2002. The primary consists of 6 Bi-2223 HTS coils with double pancake racetrack shape. The secondary is formed from 4 permanent magnets. The operation temperature for the HTS coils is $33 \mathrm{~K}$, the rated current is $150 \mathrm{~A}$, and the air gap is $12 \mathrm{~mm}$. J. Kellers et. al. develop an HTS linear motor used for industry. The BSCCO-2223 multi-fiber HTS wires are adopted. The primary consists of 36 double pancake HTS coils. The rated frequency is $25 \mathrm{~Hz}$, Max thrust is up to 6000N [32]. The researchers in Portugal developed a fully HTS linear synchronous motor. The primary coils are developed by using first generation HTS wires; whereas the secondary is composed of two single-domain YBCO bulks [33-35].

In the field of the application of the high-temperature superconducting (HTS) technology, China also makes a great progress. In 2000, prof. Wang Jiasu cooperated with Wang Suyu completed the works of the world's first man-load HTS maglev vehicle. In 2009, prof. Fang Jin with Beijing Jiaotong University developed a single-sided HTS linear induction motor used for linear metro. During the operation, the machine gained a maximum speed $3.5 \mathrm{~m} / \mathrm{s}$ and the maximum thrust $1000 \mathrm{~N}$. In the following sections, the status of the linear rail transit system in China will be detailed.

\section{MagleV Trains}

Magnetic levitation transport, or maglev, is a radically new form of transportation that suspends, guides, and propels vehicles via electro-magnetic energy. The maglev train is composed of three systems: levitated system, propulsion system and the guide system. According to the operation speed, the practical maglev trains in China can be divided into two types: the high speed maglev train $(>400 \mathrm{~km} / \mathrm{h})$ and the medium-low speed maglev train $(<200 \mathrm{~km} / \mathrm{h})$. According to the materials of the field coils, the maglev train can be divided into two types: the conventional maglev train and the superconducting maglev train. 


\section{A high speed maglev trains}

China cooperated with Germany constructed the world's first commercial operation maglev demonstration line in 2001. The line starts from the Longyang Road station in the west and ends up in Pudong international airport station, as shown in

Fig. 1. The entire line is $29.863 \mathrm{~km}$.

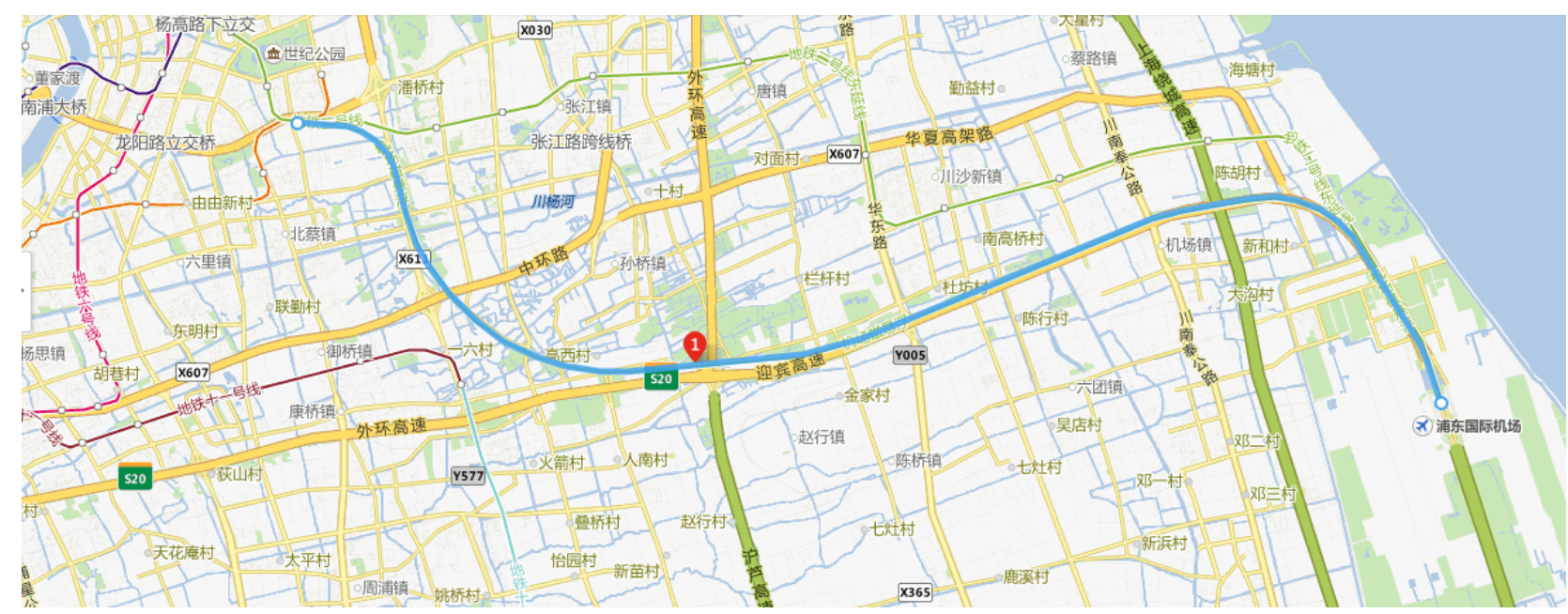

Fig. 1. Route map of Shanghai Maglev Train

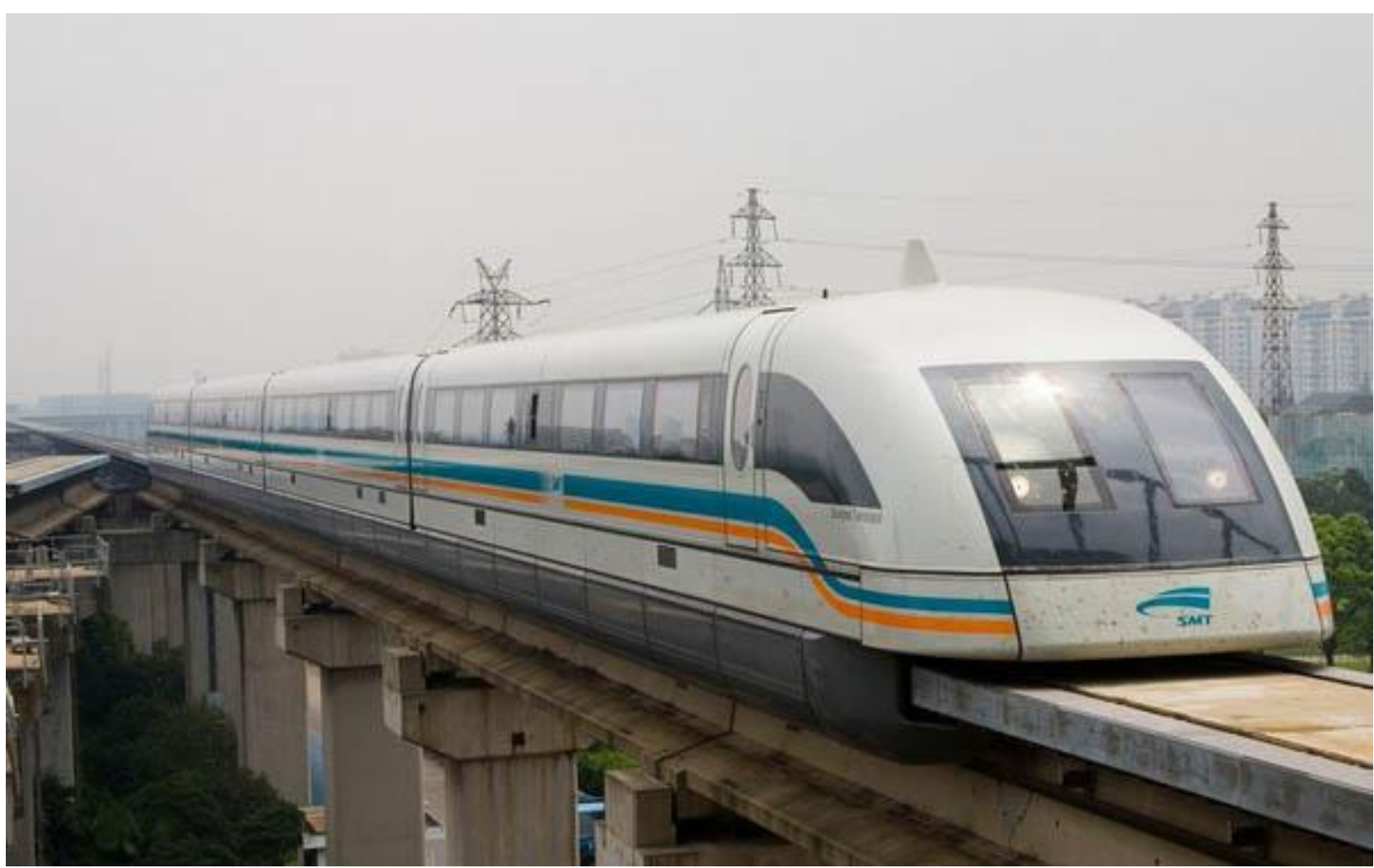

Fig. 2. Shanghai high speed maglev train 


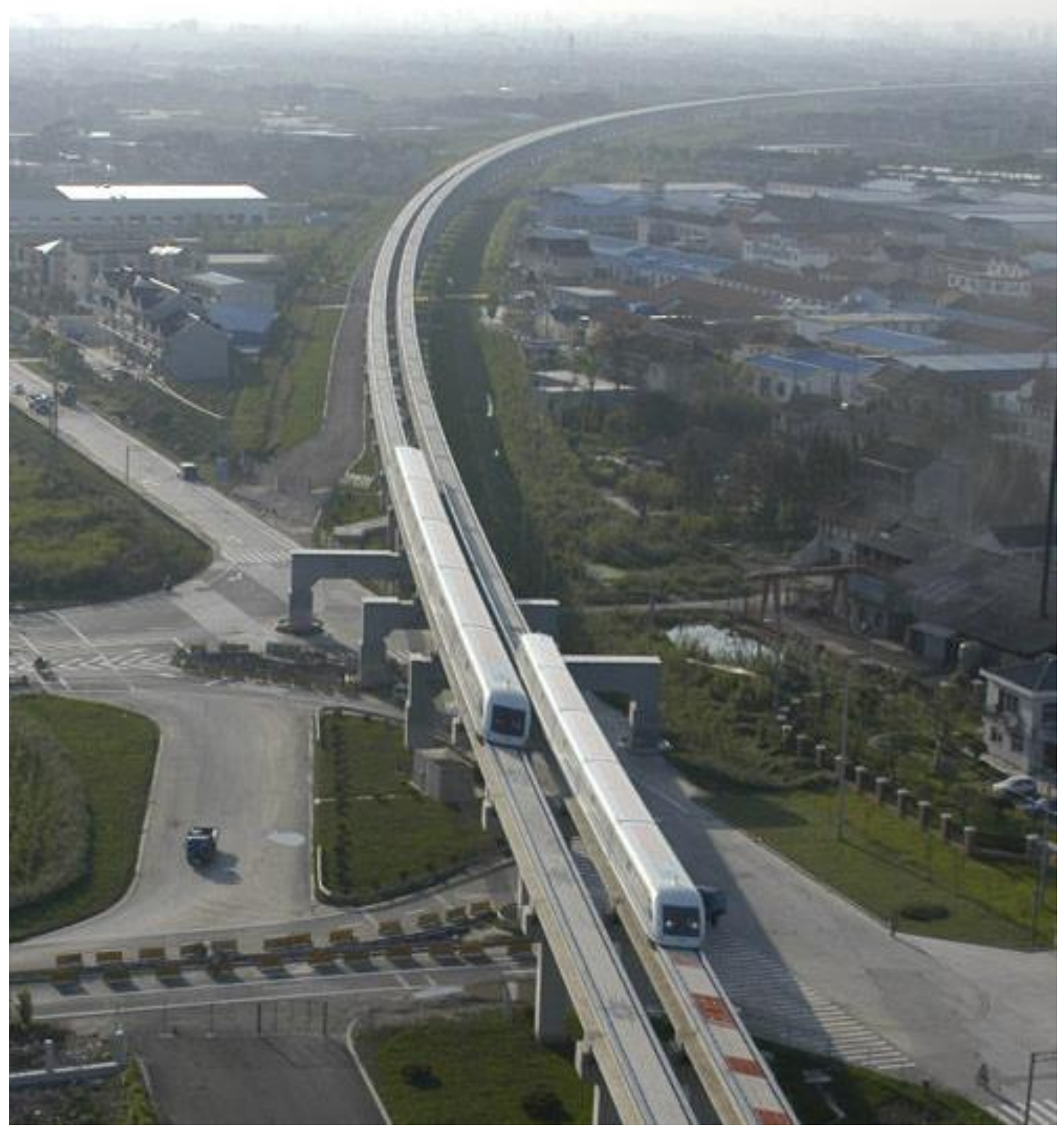

Fig. 3. Maglev train is passing through curves

The trains of Shanghai high speed maglev train is shown in

Fig. 2. The Shanghai high speed maglev train started to pre-operate in Dec. $31^{\text {st }}, 2002$. And its commercial operation began in Jan $4^{\text {th }}, 2003$. The designed maximum speed is $430 \mathrm{~km} / \mathrm{h}$, which is only less than the fly speed of the planes. During the daily operation, the operation speed is about $380 \mathrm{~km} / \mathrm{h}$. After the Yong-Wen EMU accident, the operation speed is limited to $301 \mathrm{~km} / \mathrm{h}$. The whole journey from Beijing to Shanghai only takes 8 minutes. The maximum turn radius is $8000 \mathrm{~m}$ and the minimum turn radius is $1300 \mathrm{~m}$. Thus the passengers in the trains cannot feel the train is turning. 


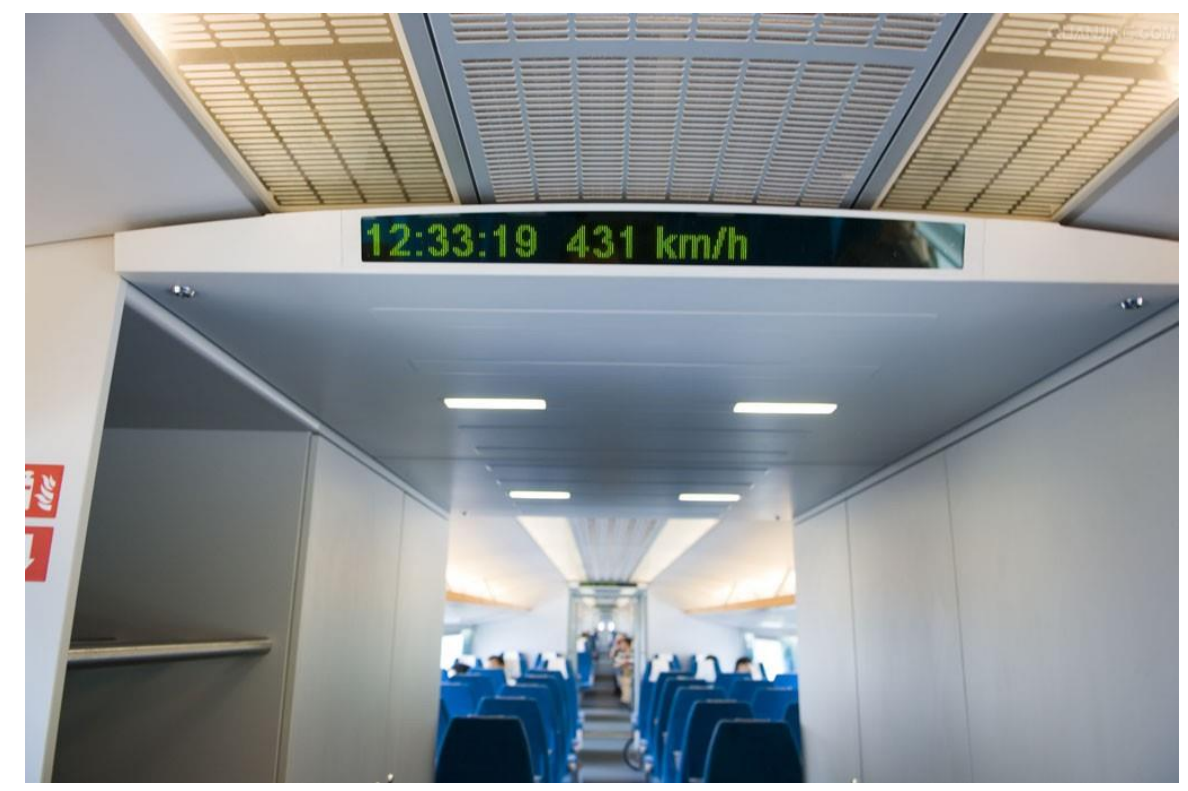

Fig. 4. Unloaded test operation of the maglev train

As shown in

Fig. 4, during the unloaded test operation, the maximum operation speed of the train achieves $431 \mathrm{~km} / \mathrm{h}$.

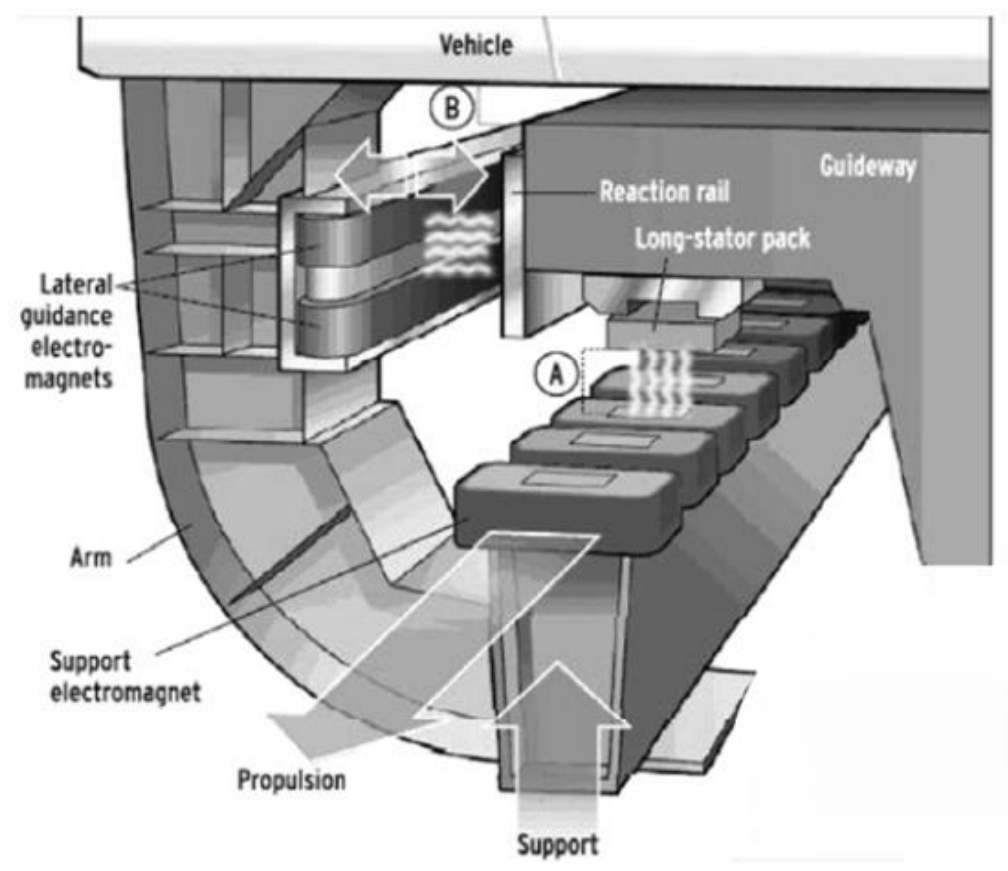

Fig. 5. Schematic diagram of the maglev train

There are three primary types of maglev technology: one that relies on superconducting magnets (electro-dynamic suspension, EDS), one that relies on feedback controlled electromagnets (electromagnetic suspension, EMS), and a 
newer potentially more economical system that uses permanent magnets (Inductrack). Japan and Germany are active in maglev research, producing several different approaches and designs. In one design, the train can be levitated by the repulsive force of like poles or the attractive force of opposite poles of magnets. The train can be propelled by a linear motor on the track or on the train, or both. Massive electrical induction coils are placed along the track in order to produce the magnetic field necessary to propel the train.

Shanghai maglev train adopted Germany technology. The field coils are developed by using conventional copper wires. The maglev train is composed of 3 subsystems: the levitated system, the guidance system, and the propulsion system. The levitated system is composed of the electromagnets installed in the bogies and the electromagnets installed along the tracks. By controlling the current of the electromagnets, the air gap is within $10 \mathrm{~mm}$. The induction plates are installed in the both side of the tracks, thus, by controlling the current of the electromagnets installed in the vehicles, the vehicles can be limited in the center of the tracks.

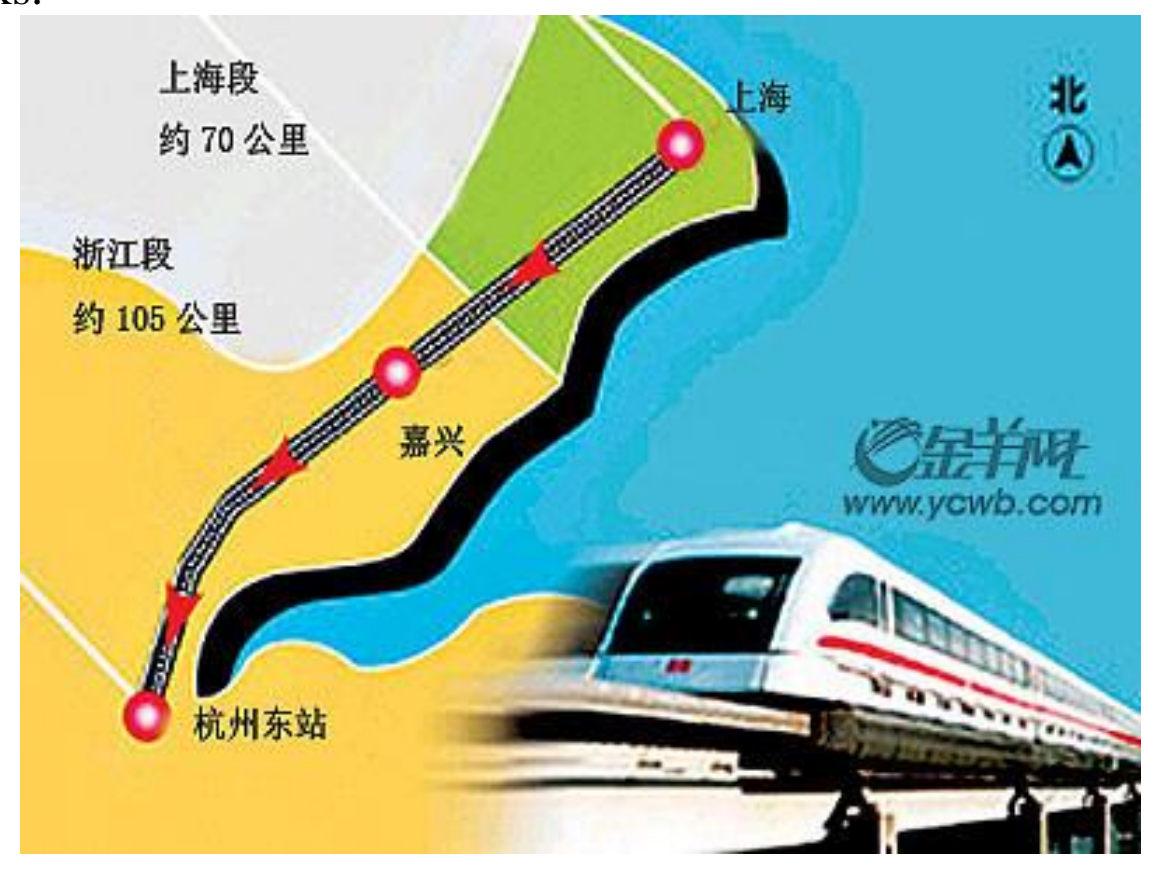

Fig. 6. Route of Shanghai-Hangzhou maglev train

After several years' operation experiences, China is considering maglev as a possible technology option for building a planned high-speed rail network to connect major cities, although the cost may make this more difficult. Talks with Germany on the possible construction of a second Transrapid maglev rail linking Shanghai to Hangzhou have started. The Shanghai-Hangzhou maglev line would become the first inter-city Maglev rail line in commercial service in the world. The line will be an extension of the only other Maglev line in commercial service, the Shanghai airport Maglev line. Shanghai-Hangzhou high 
speed maglev train had been approved in 2006. The early planning length is $175 \mathrm{~km}$. the Shanghai segment is about $70 \mathrm{~km}$ and the Zhejiang segment is about $105 \mathrm{~km}$, as shown in

Fig. 6.

The Shanghai-Hangzhou maglev train was due to start construction in 2010 and the total investment is about 22 billion Yuan (CNY). However, due to the route optimization problem, the construction was put off for several times. After several adjustments, the line was finally determined. The total line is now $199.44 \mathrm{~km}$. The Shanghai-Hangzhou maglev intercity segment is $164.58 \mathrm{~km}$ and the Shanghai segment linked to the Shanghai maglev line is $34.86 \mathrm{~km}$.

The project has not yet started because that there are still some problems to be settled: the first one is the potential risk of radiation, the designed distance from the residential area is only $22.5 \mathrm{~m}$, which is far less than the general distance $200 \mathrm{~m}$. Thus, the residents along the planning line disagree to construction of the maglev train. The second one is the safety. Since the Germany test line and the Shanghai maglev train occurs accidents, people are worrying about the safety of the maglev trains. The third one is the commercial value. The EMU travelling from Shanghai to Hangzhou takes 78 minutes. The high-speed railway takes 48 minutes. While the maglev trains takes 38 minutes, it is only 10 minutes shorter than the high-speed railway, but the cost will be several billions which is much larger than the high-speed railway. In addition, the maglev train cannot be directly connected with the existing railway system, the compatibility is less than the high-speed railway. Thus, large-scale application of high-speed maglev train is still a long way to go.

\section{B Medium-low speed maglev trains}

The medium-low speed maglev trains is aimed to the intercity railway. The operation speed is below $200 \mathrm{~km} / \mathrm{h}$. compared with the high-speed maglev trains, it is energy saving, friendly with the environment, low construction cost. It can be used to instead of the light railway and the subway. The research on the maglev trains in China begins 1980s. China's first maglev trains test line was developed by the researchers in Southwest Jiaotong University in Oct. 1994. The prototype train has 7 seats, the levitated height is $8 \mathrm{~mm}$, and the total weight is $4 \mathrm{t}$. The operation speed is $30 \mathrm{~km} / \mathrm{h}$. the project of the Qingchenshan maglev train demonstration line was approved in 1998. And the construction was begun in Apr. 2001. The train operated in the rails was succeeded testing in Apr. 30 ${ }^{\text {th }}$, 2006. The whole line of the Qingchengshan demonstration line is $419.925 \mathrm{~m}$ and the gross investment is 30 million. The Qingchenshan demonstration line is the first maglev train designed, developed, and constructed all by China itself. Qingchenshan medium-low speed maglev train line is electromagnetic attractive active levitated trains. The train has two operation models: automatic control 
model and the driver control model. The total weight of the train is $18 \mathrm{t}$, the levitated height is $8-10 \mathrm{~mm}$ and there are 28 seats in the train. The total capacity is 60 persons.

Fig. 7 shows the Qingchenshan maglev train.

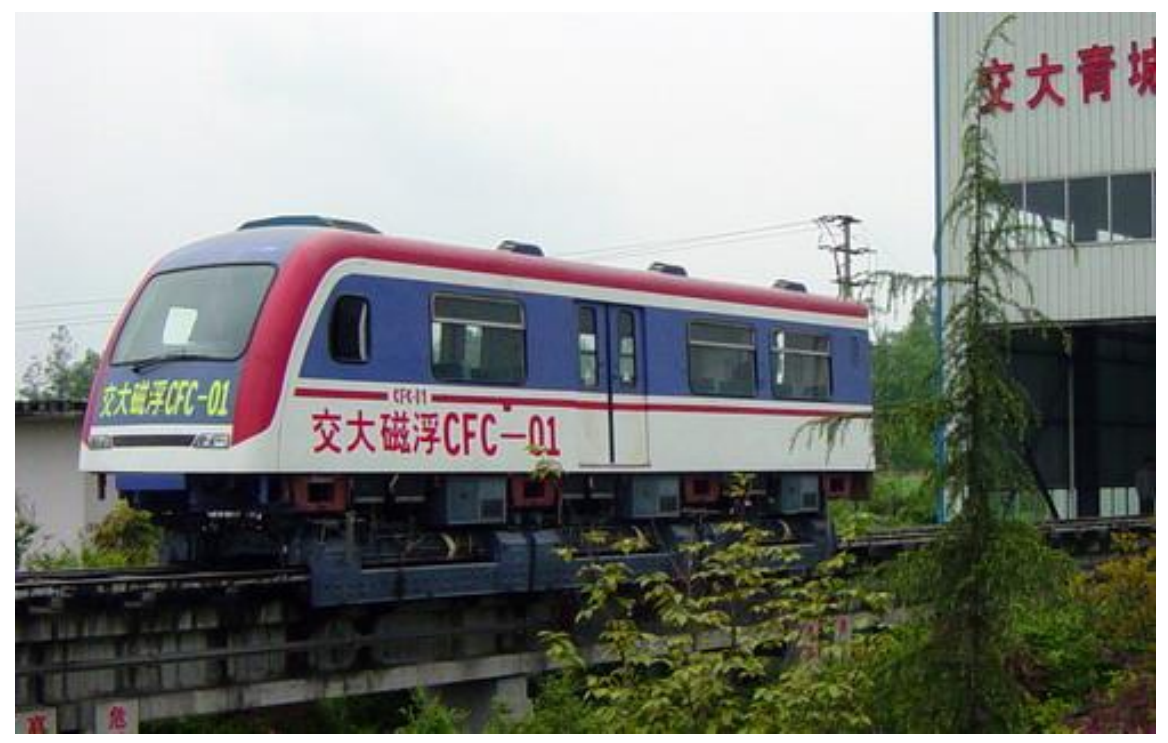

Fig. 7. Qingchenshan maglev train

China's first medium-low speed maglev train was completed by the researcher in National University of Defense Technology in Sep. 2001. The test line is $204 \mathrm{~m}$, and a turning with radium of $100 \mathrm{~m}$ and a slope with $40 \%$ gradient was constructed. The test line can meet all the test works for the maglev trains. The maglev trains developed by National University of Defense Technology are 20t. The vehicle is $15 \mathrm{~m}$ and the width is $3 \mathrm{~m}$. The max load is up to $10 \mathrm{t}$. Each unit has 44 seats and the train can load more than 130 persons. The designed operation speed is $150 \mathrm{~km} / \mathrm{h}$. After $200 \mathrm{~km}$ test works, the train can even operate very well. And all the technical performance is good; the prototype train has reached to the actual operating line standard. The maglev train can become a new type of transportation. The test line of China's first medium-low speed maglev train developed by National University of Defense Technology was shown in

Fig. 8. 


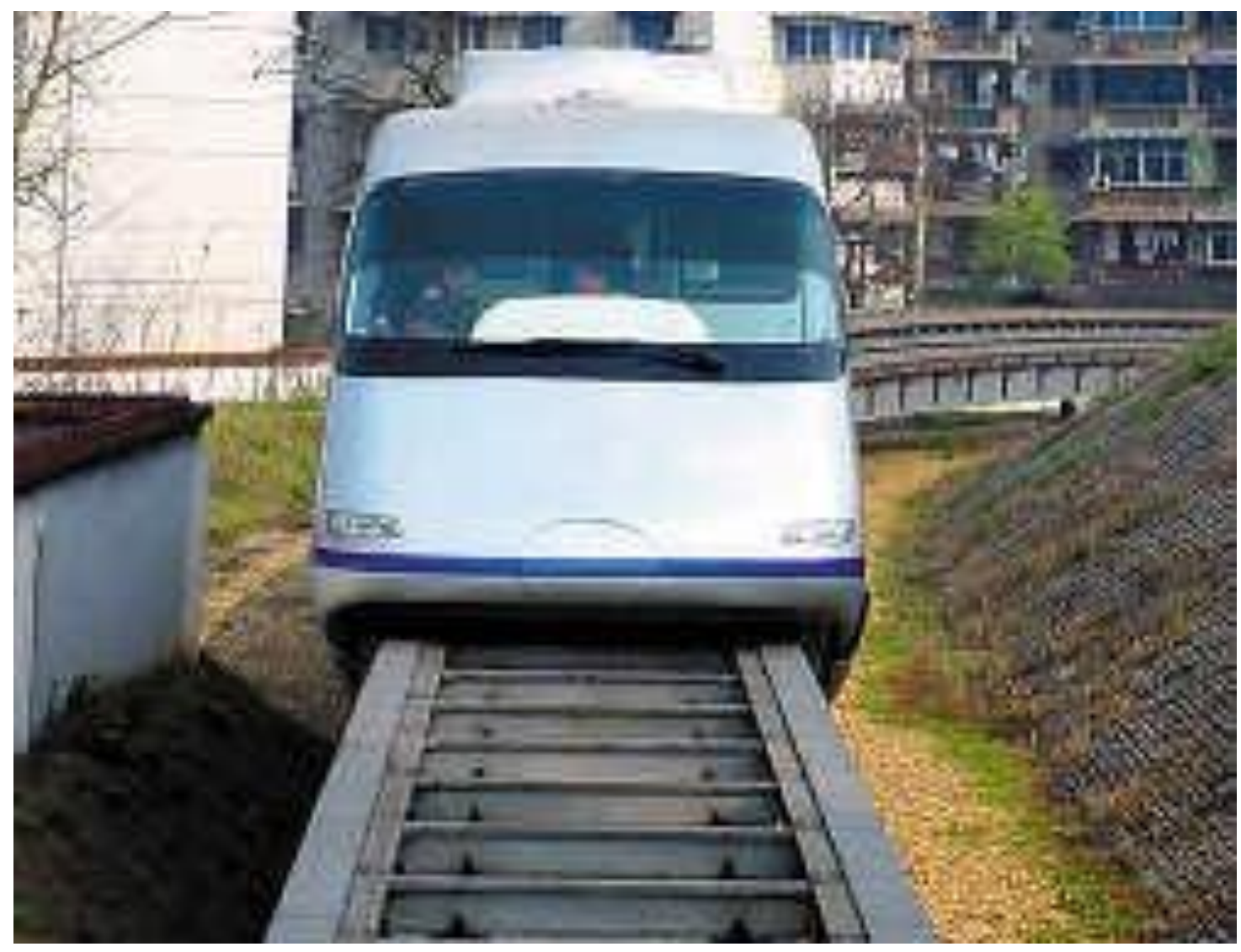

Fig. 8. China's first medium-low speed maglev train test line

The medium-low speed maglev train aimed to pratical applications was constructed by Tangshan railway vechile co., LTD, Beijing holding magnetic levitation technology development co., LTD, and National University of Defense Technology in May $13^{\text {th }}, 2009$. And then the test works were carried out immediately. The train has 3 units. It is composed of two side vehicles with the same structure and an intermediate vehicle. The operation speed is about 100$120 \mathrm{~km} / \mathrm{h}$. the side vehicles can carry 100 persons, whereas the intermediate vehicle can carry 120 persons. The service life is over 25 years. The train is supplied by DC $1500 \mathrm{~V}$. the maximum slope gradient is $70 \%$, the truning radium of the line is $50-100 \mathrm{~m}$.

Fig. 9 shows the developed practical medium-low speed maglev train . 


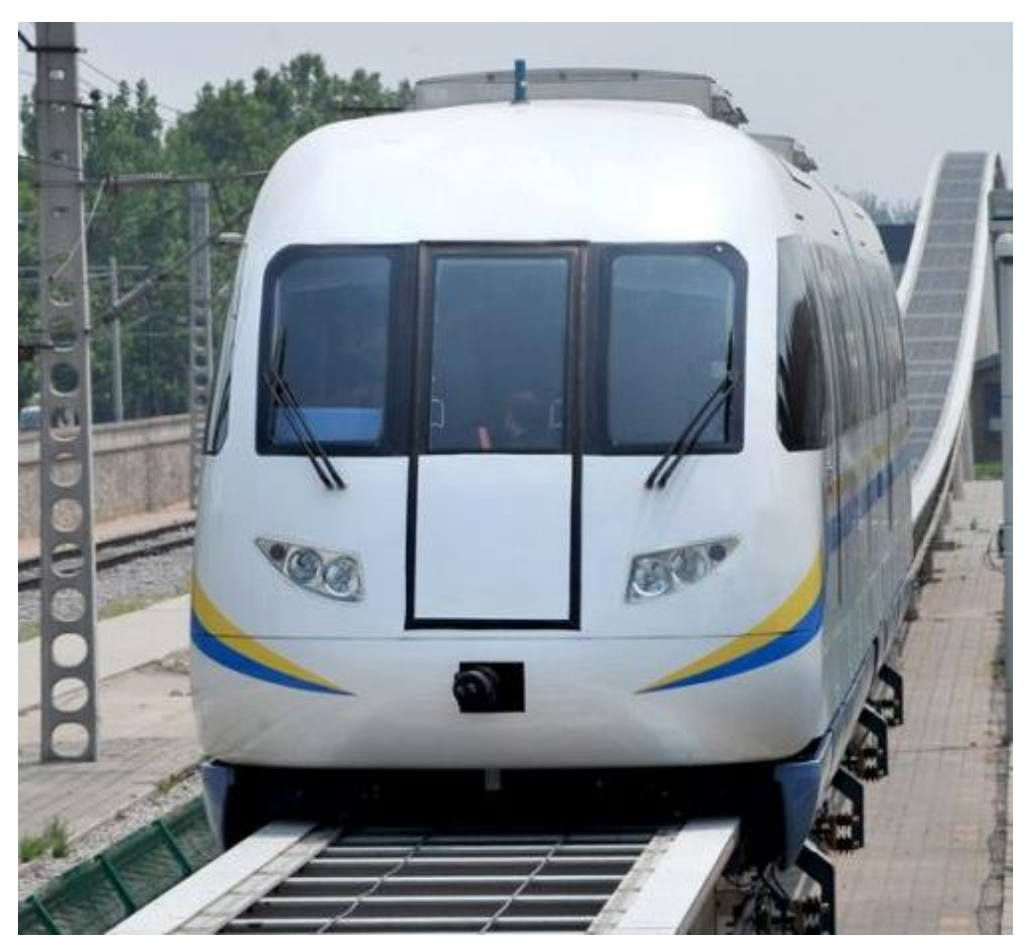

Fig. 9. Practical medium-low speed maglev train

\section{Applications of medium-low maglev train}

Beijing subway line $\mathrm{S} 1$ is the first rail transit which adoped the mediumlow speed maglev technology. As shown in

Fig. 10, Beijing subway line S1 starts from the Cishousi station in the east connected with Beijing subway line 6, passes through Haidian and Shijingshan, and ends up in the Shimenying station in the west. The entire line is $19.985 \mathrm{~km}$. Beijing subway line S1 was supposed to start in Dec. $28^{\text {th }}$, 2010. But, the construction was ceased due to the problems such as the selection of the trains, disagreement of the environment protect, and the resettlement of the residents lived along the planning line. The medium-low speed maglev demonstration line (S1) project was approved by the Beijing city development and reform commission (NDRC) in Oct. 2013. And then the stagnant project were returned to work. The whole project is expected to complete in 2015. 


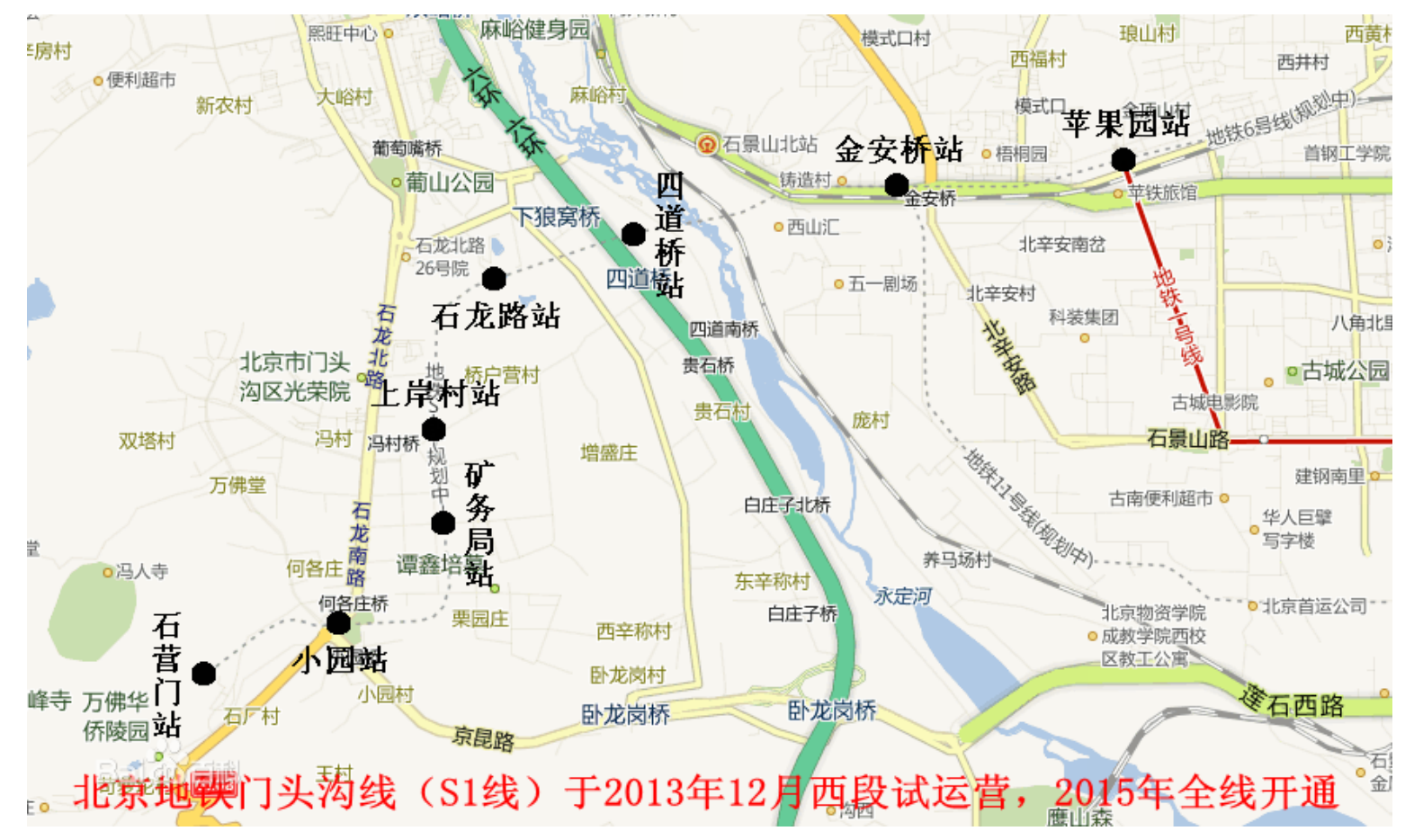

Fig. 10. Route of Beijing subway line S1

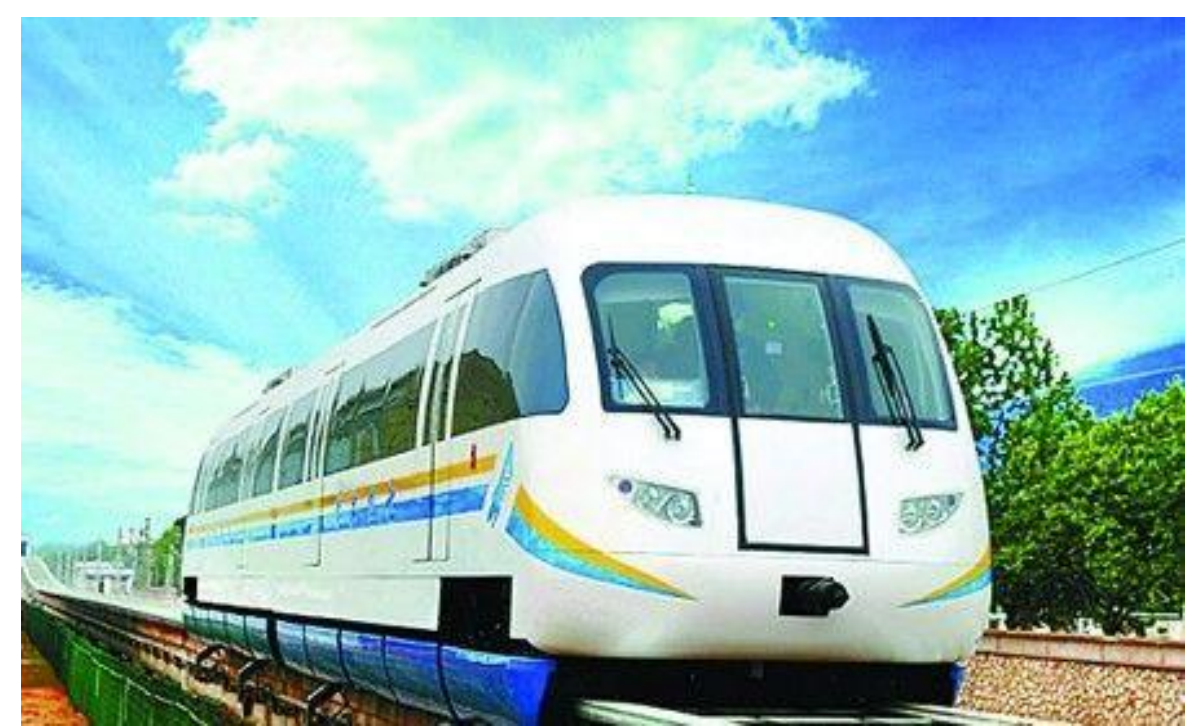

Fig. 11. Medium-low speed maglev train running in Beijing subway line S1

The medium-low speed maglev train running in the $\mathrm{S} 1$ in future is developed by Beijing holding magnetic levitation technology development co., LTD, and National University of Defense Technology. The developed mediumlow speed maglev train is shown in

Fig. 11. The parameters of the medium-low speed maglev train is outlined as follows: maximun operation speed $100 \mathrm{~km} / \mathrm{h}, 6$ units, length of the train $89.6 \mathrm{~m}$, capacity of the train 1032 persons. The gross investment of the project is 
6.42 billion. The investment used for environment protect is 94.78 millon, about $1.48 \%$ of the gross investment.

Besied Beijing, another city Changsha has also planning to develop a medium-low speed maglev line. The planning route of Changsha medium-low speed maglev train is shown in

Fig. 12. The line starts in the north of the East Squre in Changsha south train station, along the Laodong Road, Huangxing Avenue, and airport express, the terminal station is the Huanghua airport station. The line is $18.7 \mathrm{~km}$, the whole line is elevated. The gross investment is about 4.2 billion.

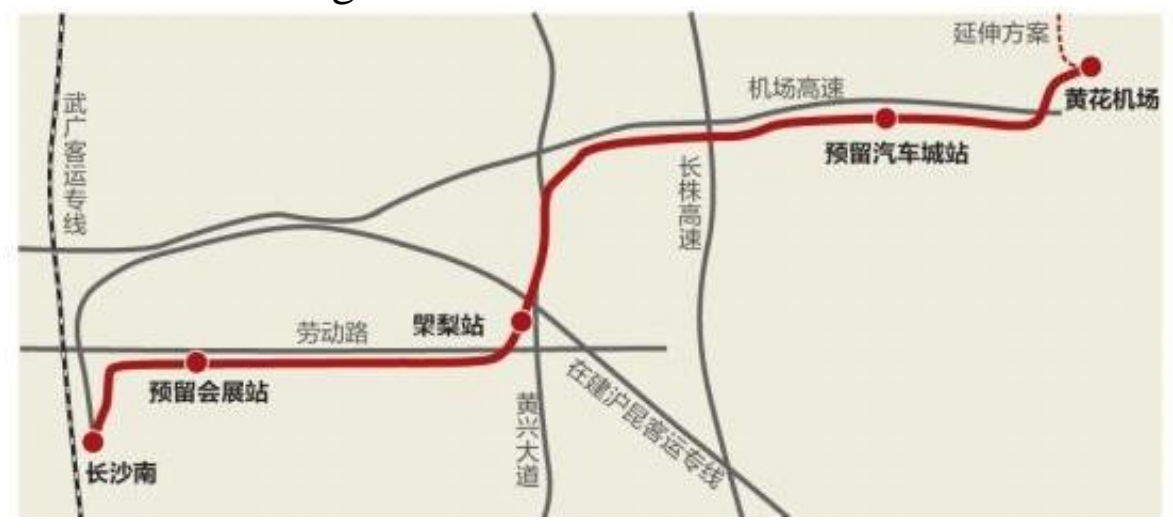

Fig. 12. Planning route of Changsha medium-low maglev train

The formal construction of the Changsha medium-low speed maglev train begins in May $16^{\text {th }}, 2014$, and it is planning to operate in 2016. Fig. 13 shows the Changsha medium-low speed maglev train. The train is constructed by CSR. The train has three vehicles in a unit, and the maximum speed is $120 \mathrm{~km} / \mathrm{h}$. When the project is completed, passengers travelling from Changsha South Station to Huanghua Airport T2 terminal only take 10 minutes.

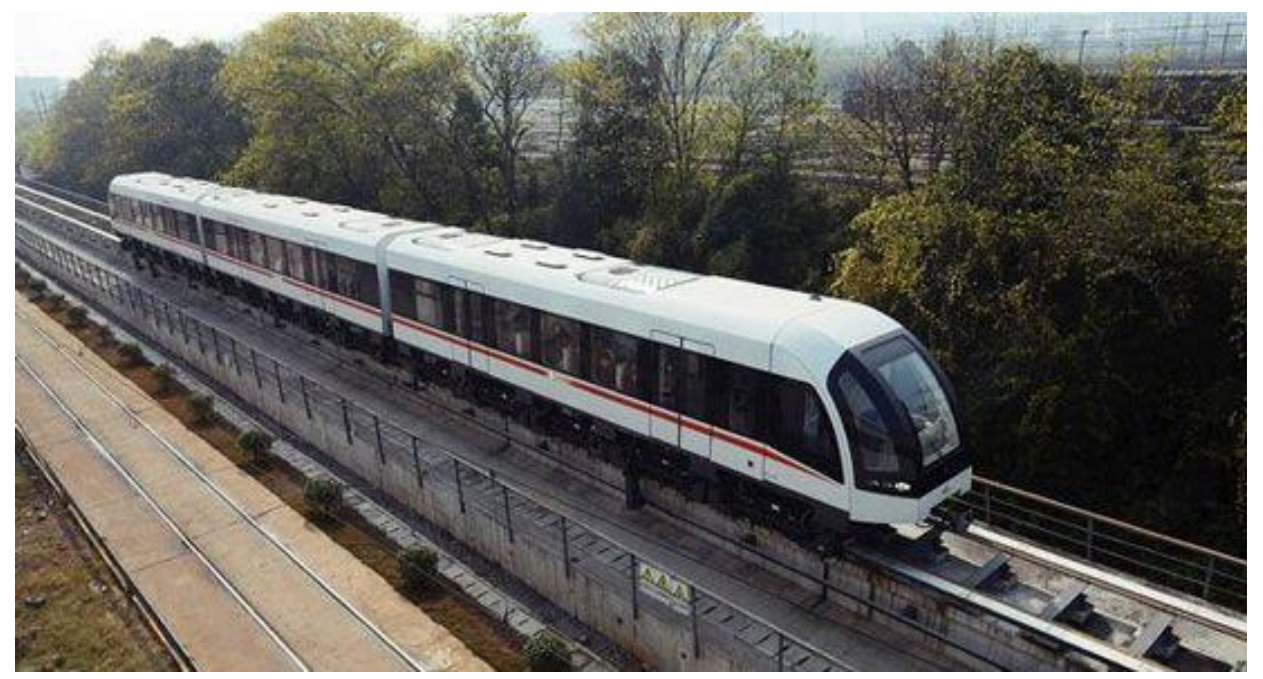

Fig. 13. Changsha medium-low speed maglev train 
According to the estimate, the comprehensive cost of the medium-low speed maglev train system is about 1150-250 milion Yuan per kilometer, it is only $2 / 3-3 / 4$ of the cost of the light rail system in the same area. Since the train is not contacted directly with the rails, thus, the noise is below $62 \mathrm{~dB}$. When it is passing from us, even stood 3 meters, we cannot feel any noise. When the medium-low speed train is $1 \mathrm{~m}$ from us, the radiation is lower than that of the domestic induction cooker. If the distance is extended to $5 \mathrm{~m}$, the radiation is less than the electric shaver. When the distance is larger than $10 \mathrm{~m}$, the radiation even can not be detected by the professional testing instrument.

China's other cities are planning to build the medium-low speed maglev train. Shenzhen city is planning to construct the subyway line 8 which will adopt the medium-low speed maglev train. Tianjin is undertaking the selection of the medium-low speed maglev line. Jinan, Luoyang, Chongqing, et. al. are planing to construct the medium-low speed maglev trains

\section{LiNEAR METRO}

Linear metro is rail transportation propelled by linear motor; supported and guided by the rail/wheel system. The technology can rebuilt on the original rails, thus the cost is far low than the maglev trains. Thus, its applications is expanding year by year.

\section{A Guangzhou metro line 4}

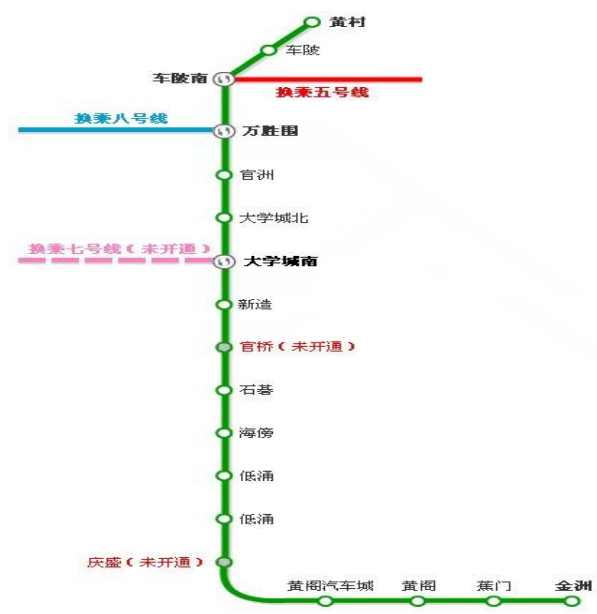

Fig. 14. Route of Guangzhou metro line 4

The Guangzhou metro line 4 is the first linear metro propelled by linear motors. The whole line is $46 \mathrm{~km}$; the segment underground is $16 \mathrm{~km}$, the segment overhead is $30 \mathrm{~km} .18$ stations were set up in the line, as shown in Fig. 14. The segment from Wanshengwei to Xinzao was completed in Dec. $26^{\text {th }}, 2005$. The Xinzao-Huangge segment was finished in Dec. $30^{\text {th }}, 2006$; Jiaomen station and 
Jinzhou station were put into service in Jun. $28^{\text {th }}, 2007$; the segment from Waishengwei to Chebi south was finished in Dec. $28^{\text {th }}, 2009$; and the Chebi south-Huangcun segment was completed in Sep. $25^{\text {th }}, 2010$. From then on, the whole line was completed.

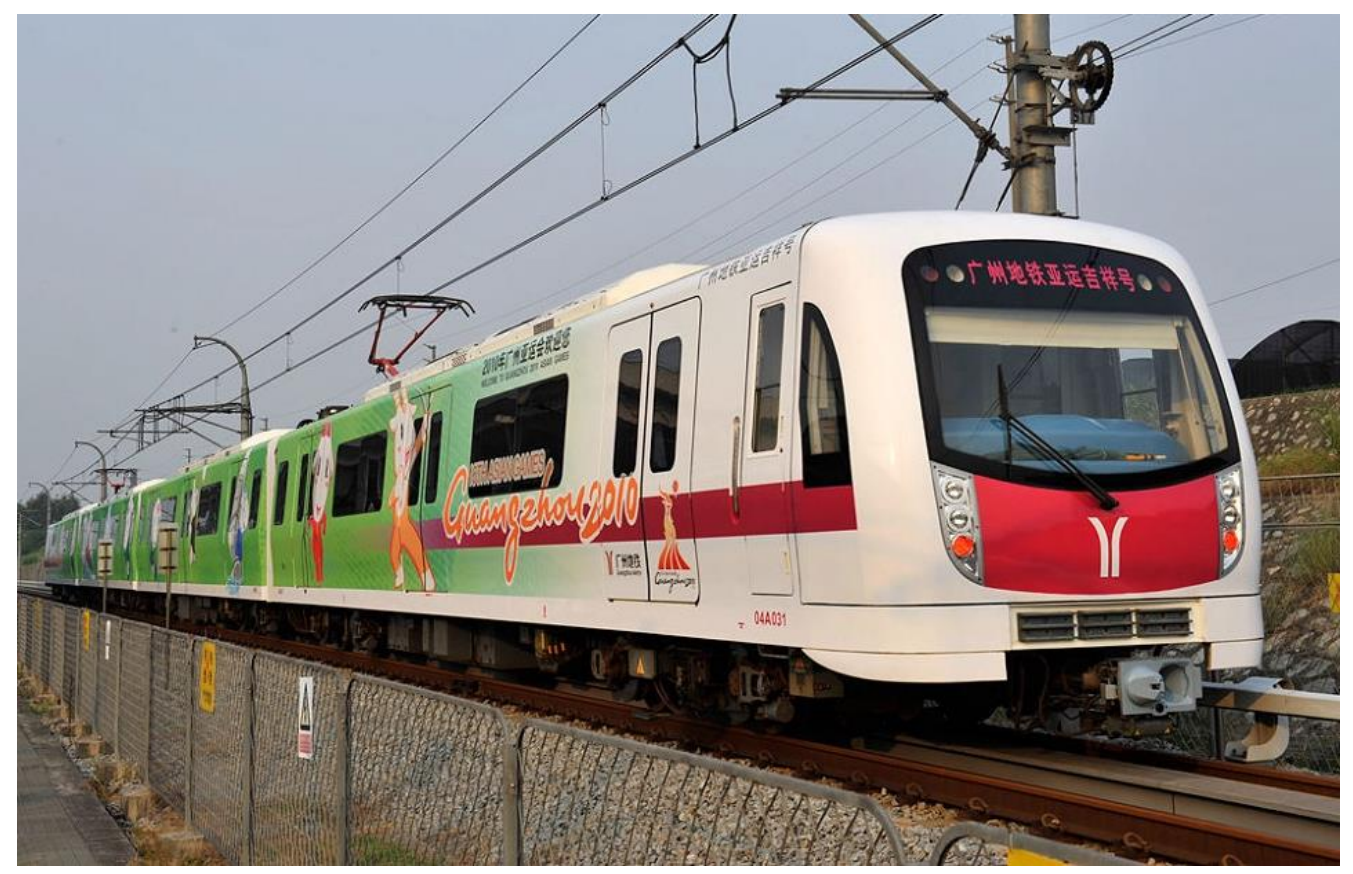

Fig. 15. Linear train in Guangzhou metro line 4

The linear train running in Guangzhou metro line 4 was shown in Fig. 15. The train was developed by CSR Sifang co., Ltd cooperated with Kawasaki Heavy Industries co., Ltd. The vehicle adopted the model "L", 4 units. The entire train is $71 \mathrm{~m}$ long, $2.8 \mathrm{~m}$ wide and the maximum operation speed is $90 \mathrm{~km} / \mathrm{h}$. The climbing capacity is $70 \%$, 3 times than the conventional train propelled by rotation motors. The minimum turning radius is only $60 \mathrm{~m}$. The train has high ability to overcome faults. When the train loses $1 / 4$ power, it can still run a double line length with rated carrying capacity; when it loses $1 / 2$ power, it can be started at 60\% slope with rated carrying capacity and can be operated to the nearest station.

Fig. 16 shows the view of the station in Guangzhou metro line 4. The power is supplied by pantograph and the power pick-up shoe. In the open air segment, the power is supplied by the flexible catenary, thus, it can guarantee safety of the maintainers. While in the tunnel, the power is supplied by using the third rail to reduce the works of the project. Due to the light weight and contactless to the rails, the noise during the operation process is much lower than the rotary motor vehicles. The journey taken the linear metro will be more quiet and comfortable. 


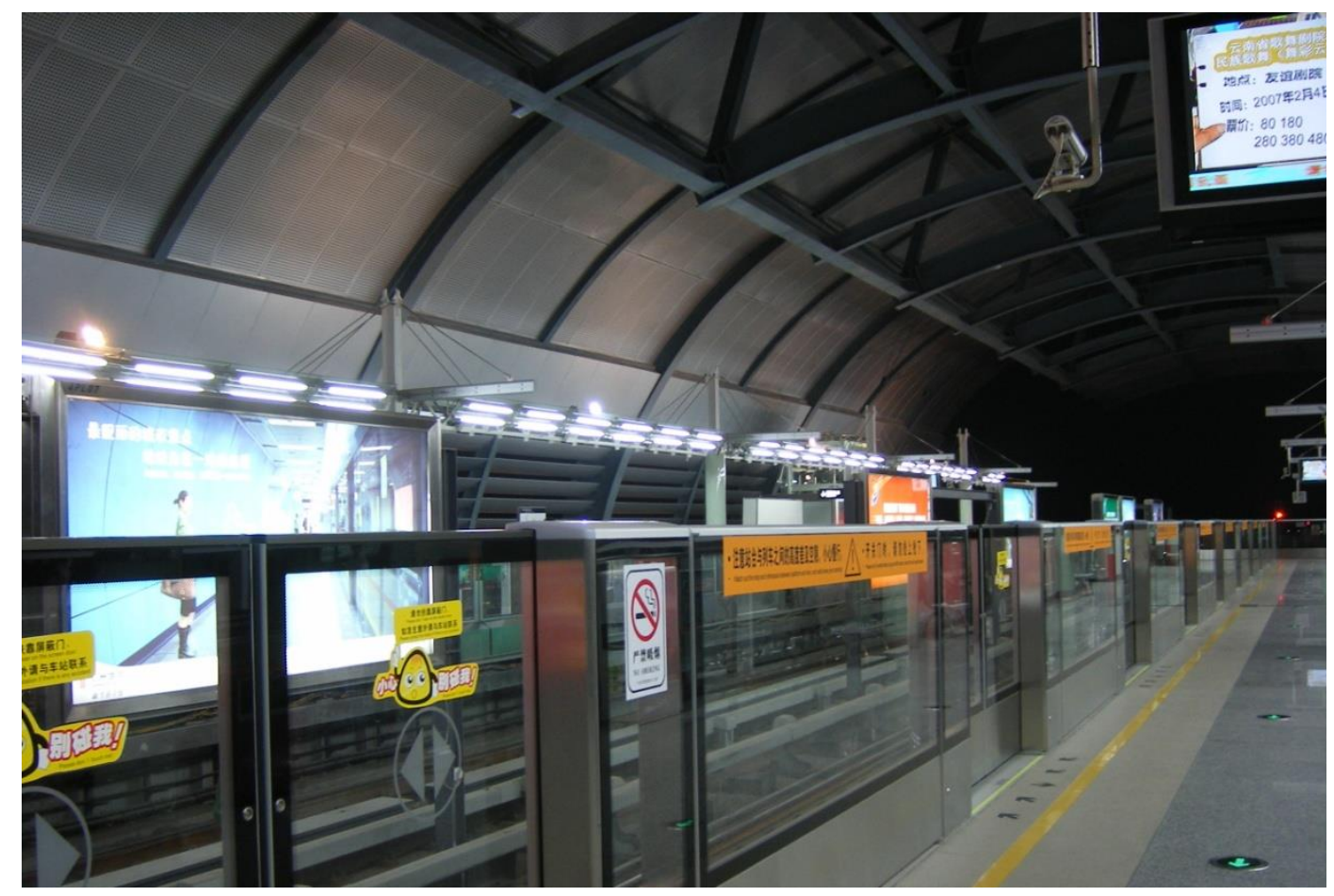

Fig. 16. View of the station in Guangzhou metro line 4

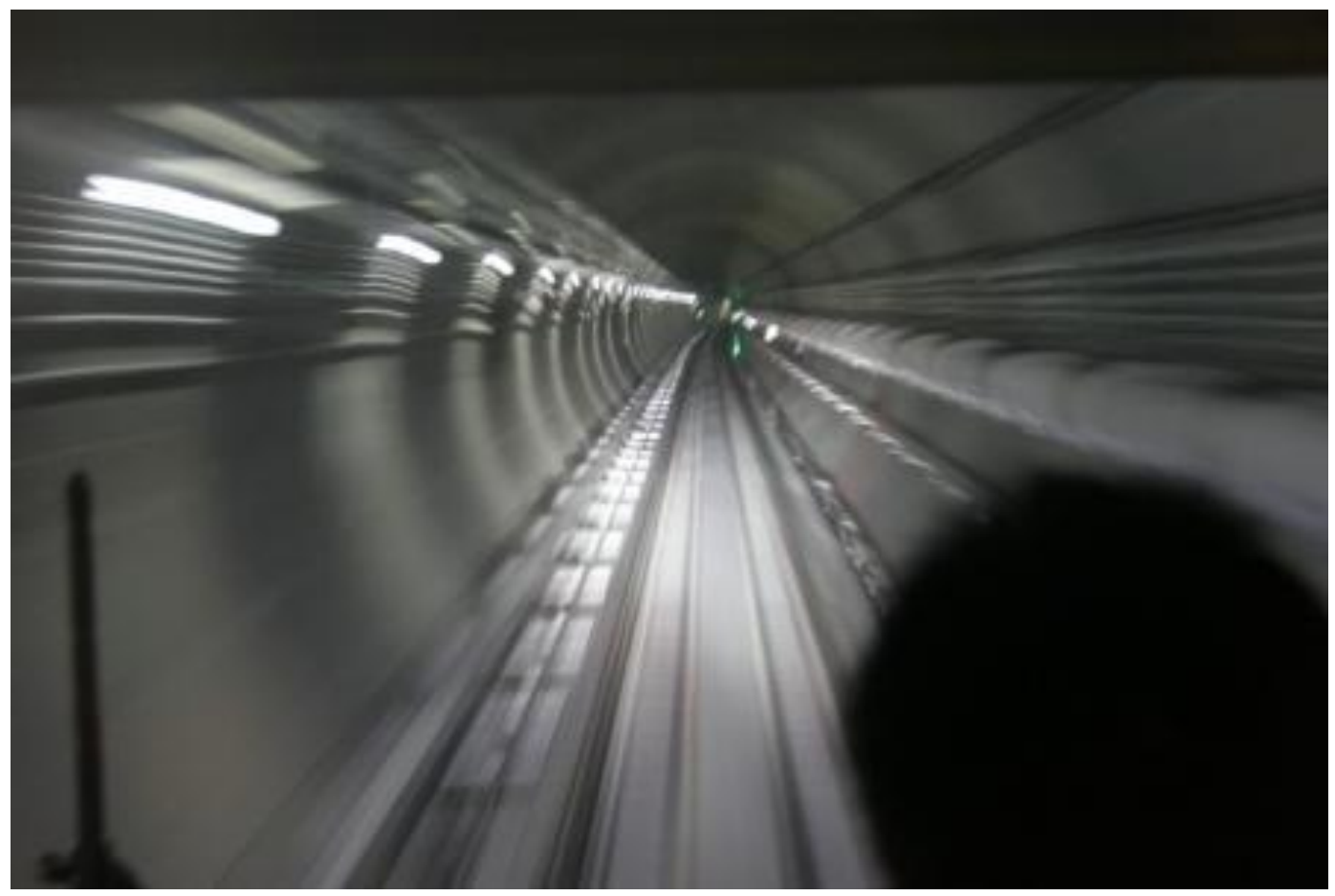

Fig. 17. Linear metro is accelerating in the tunnel

The average acceleration of the Guangzhou metro line 4 during the starting up process is larger than $1.0 \mathrm{~m} / \mathrm{s}^{2}$, so the train can reach up to the operation speed in a few seconds. Fig. 17 shows the acceleration process of the 
train in the tunnel. The emergency braking deceleration is over $1.3 \mathrm{~m} / \mathrm{s}^{2}$. The train with over load can stop in the slop gradient of $60 \%$, and the train without any load can stop in the slop gradient of $70 \%$.

Fig. 18 shows the main control system of Guangzhou metro line 4. The main control system is composed of the central main control system (CMCS) set in Dashi and Xinzao control center, the soft testing platform (STP) and the Network management system (NMS) in Xinzao control center, the station main control system (SMCS), depot main control system (DMCS), and the training management system (TMS). The MCS adopts two level of management and three level of control distributed structure. The two level of management is central management and station management. The three level of control is central control, station control, and the work field control.

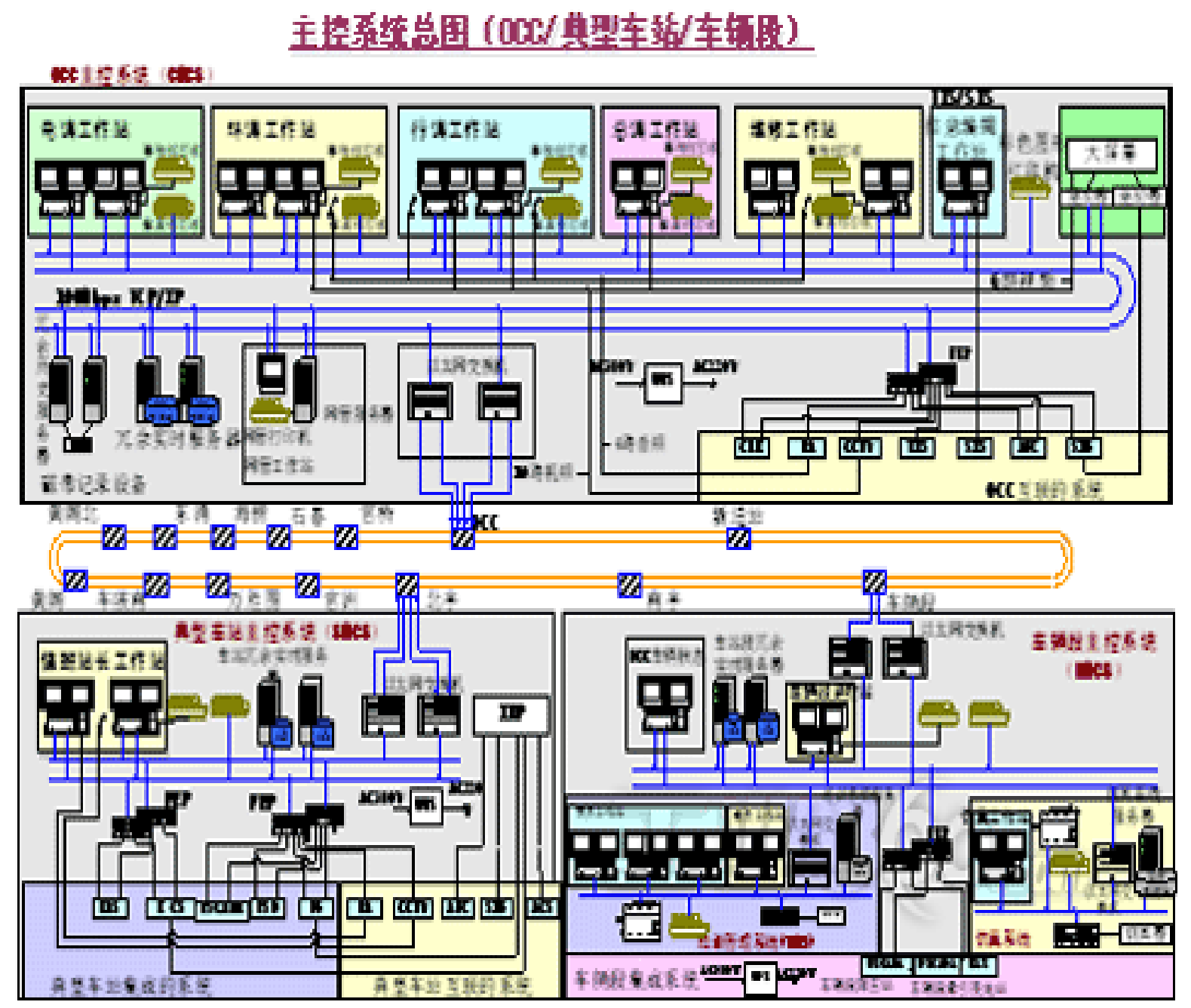

Fig. 18. Main control system of Guangzhou metro line 4 
广州市轨道交通四号线南延段（金洲至南沙客运港）线路走向见图 1-1。

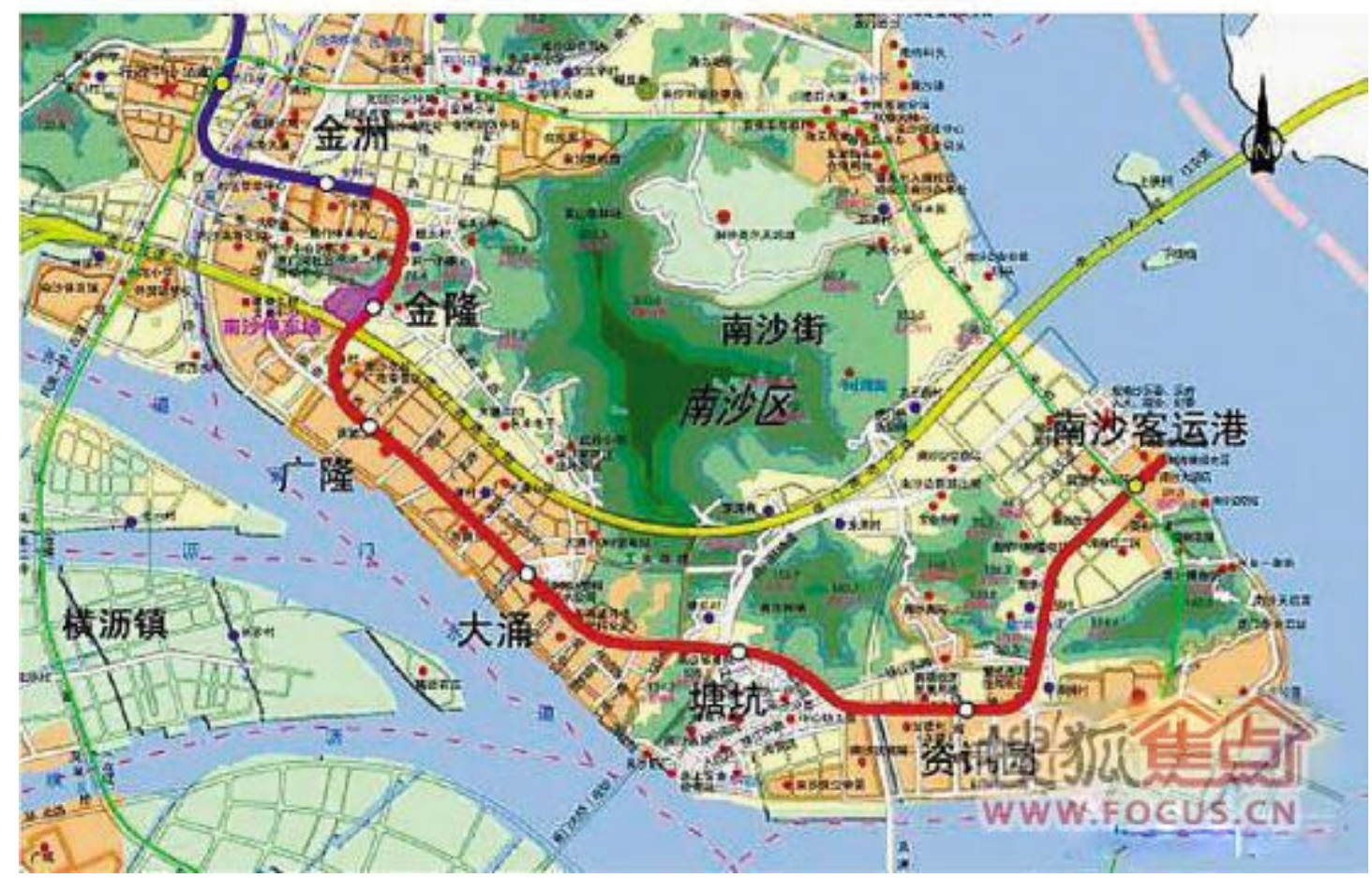

Fig. 19. Route of south section of Guangzhou metro line 4

The south section of Guangzhou metro line 4 was started in Jun. 19th, 2013 and it is expected to be completed in 2016. The south section line starts from Jinzhou station and the terminal is the Nansha port, as shown in Fig. 19. The line is $12.6 \mathrm{~km}$; all the lines are constructed underground. The train is the same with that operating in Guangzhou metro line 4. The max operation speed is $90 \mathrm{~km} / \mathrm{h}$.

\section{B Airport Beijing City}

The Airport Beijing City is a passenger railway line connected with the Beijing Capital International Airport (BCIA) and the Dongzhimen traffic hub. The Airport Beijing City began was started to construct in Jun. $1^{\text {st }}, 2005$ and finished in July, 2008, before the Beijing Olympic Games.

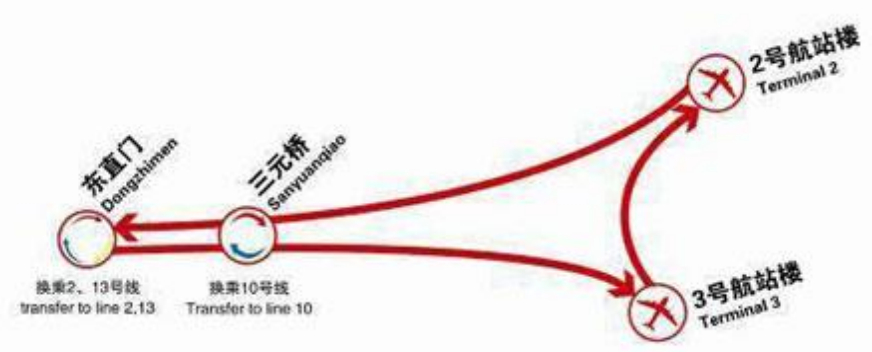

Fig. 20. Traffic map of the Airport Beijing City 
As shown in Fig. 20, the Airport Beijing City starts from Dongzhimen station in the west and the terminal is the BCIA T3 station in the east. The entire line is $28.1 \mathrm{~km}$. There are 4 stations, Dongzhimen, Sanyuanqiao, T2, and T3 station. The max operation speed is $110 \mathrm{~km} / \mathrm{h}$. the journey of the whole line takes only 16 minutes. The gross investment of the ABC is 6.223 billion Yuan.

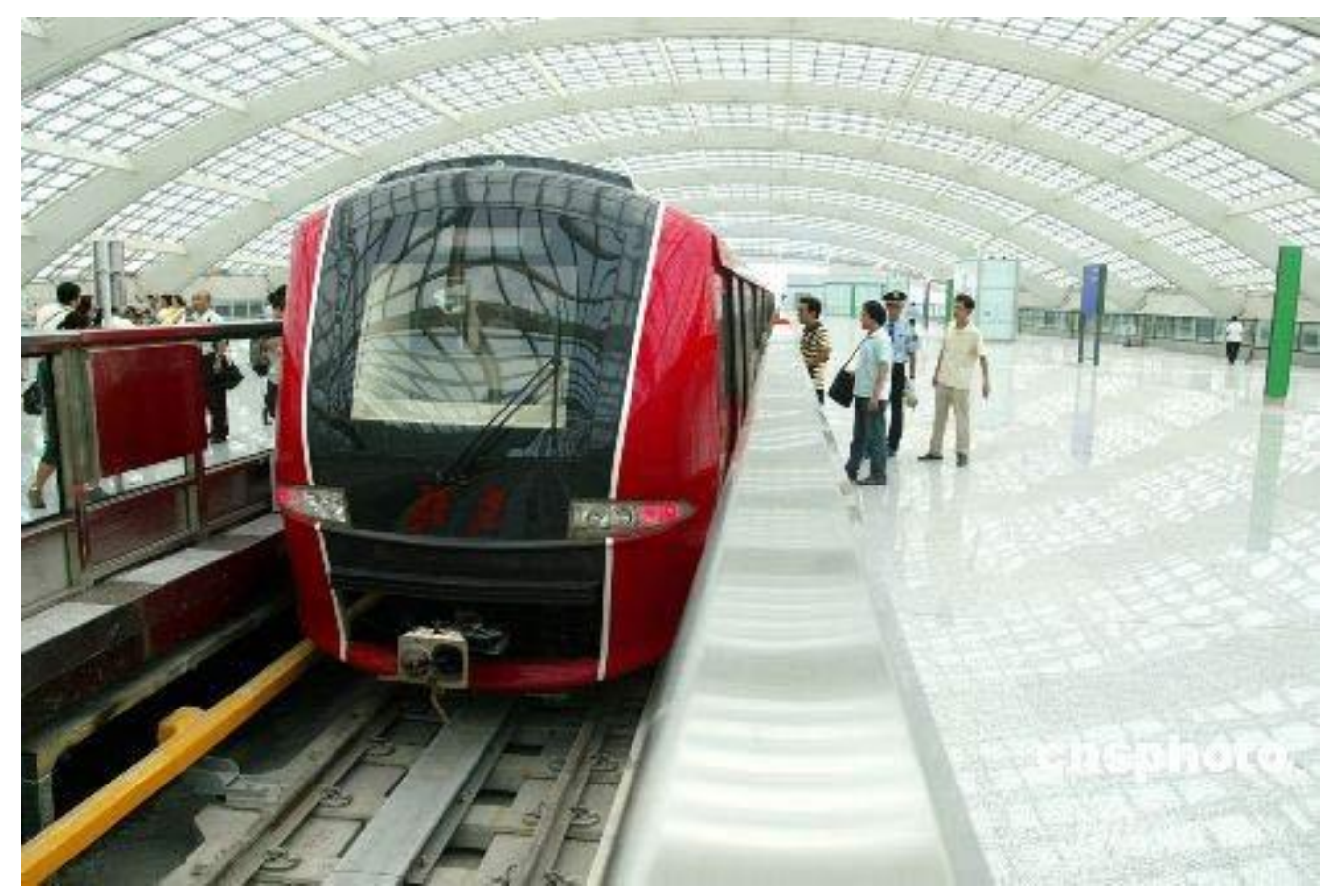

Fig. 21. Trains running in Airport Beijing City

The train running in Airport Beijing City is shown in Fig. 21. The linear motor is constructed by CSR Qingdao Sifang co. Ltd. The train is supplied by the third rail. The rated voltage is DC $750 \mathrm{~V}$. The train is marshaling by 4 vehicles. All vehicles are motive vehicle. The train is $67.7 \mathrm{~m}$ long, $3.2 \mathrm{~m}$ wide and $3.78 \mathrm{~m}$ high. The fixed wheelbase is $1.9 \mathrm{~m}$. The max speed is $110 \mathrm{~km} / \mathrm{h}$, but the average operation speed is $80.4 \mathrm{~km} / \mathrm{h}$. The train has 224 seats, the max capacity of the train is 772 persons $\left(6\right.$ persons $\left./ \mathrm{m}^{2}\right)$.

\section{Application OF HTS TECHNOLOGy to LRTS}

\section{A HTS maglev trains}

The applications of HTS technology to LRTS started early in China. On December 31, 2000, the first crewed high-temperature superconducting maglev train was tested successfully at Southwest Jiaotong University, Chengdu, China. This system is based on the principle that bulk high-temperature superconductors can be levitated or suspended stably above or below a 
permanent magnet. The YBCO bulks $(77 \mathrm{~K})$ constructed by Domestic manufacturer were utilized. When the load is $530 \mathrm{~kg}$, the levitated height is 20mm. Fig. 22 shows the scenes citizens are experiencing the HTS maglev train.

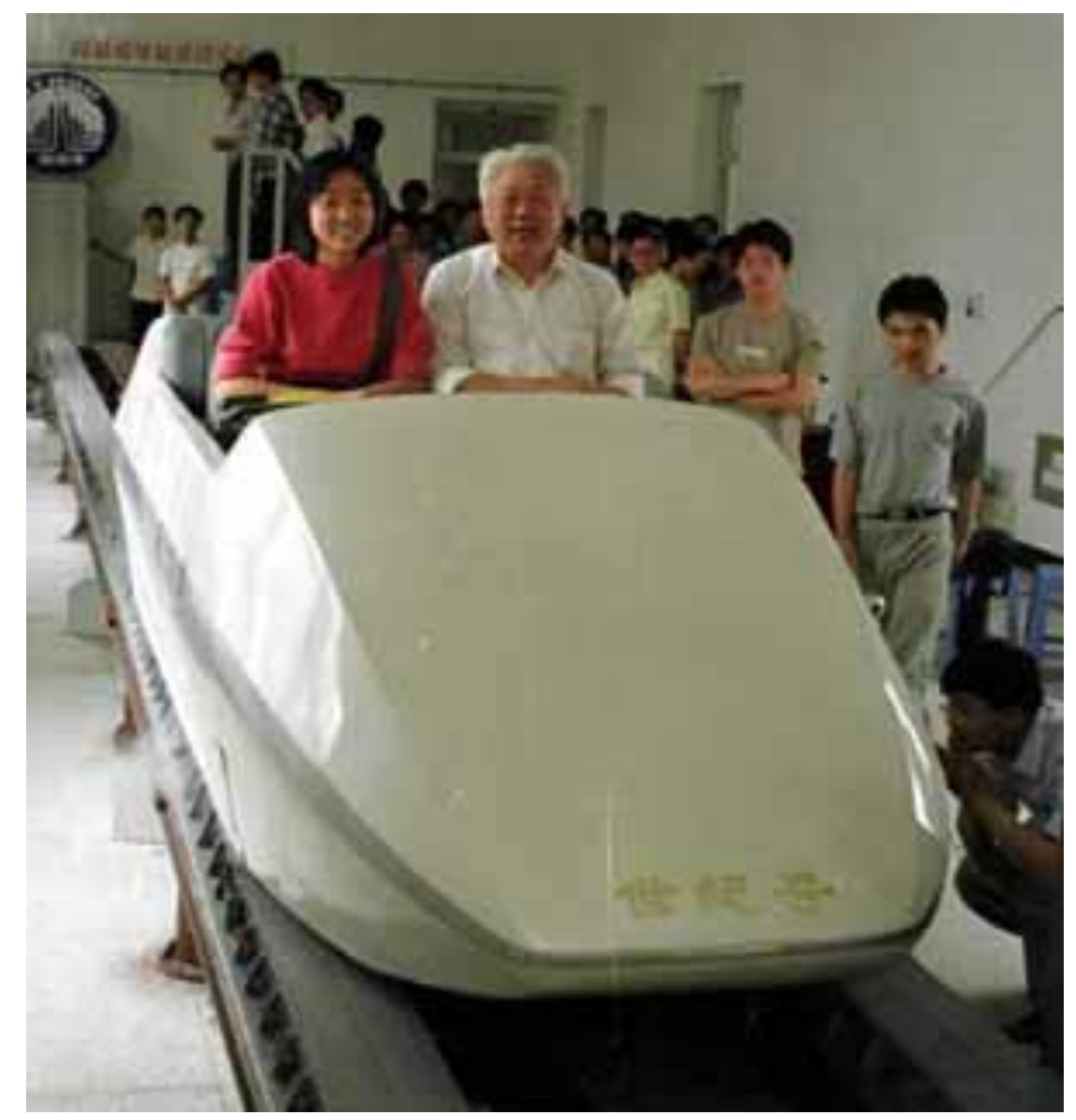

Fig. 22. Citizens are experiencing HTS maglev train

Based on the Century HTS maglev train, the scholars in China proposed another comprehensive HTS maglev train system, as shown in Fig. 23. The primary is developed by copper wires and is installed along the rail tracks. The secondary is constructed by using HTS bulk arrays. The HTS bulk array in the center interacts with the primary coils and produced the thrust to propel the train. The HTS bulk arrays in the side of the rail interact with the permanent magnets installed in the rails to produce the levitated force and the guided force. 


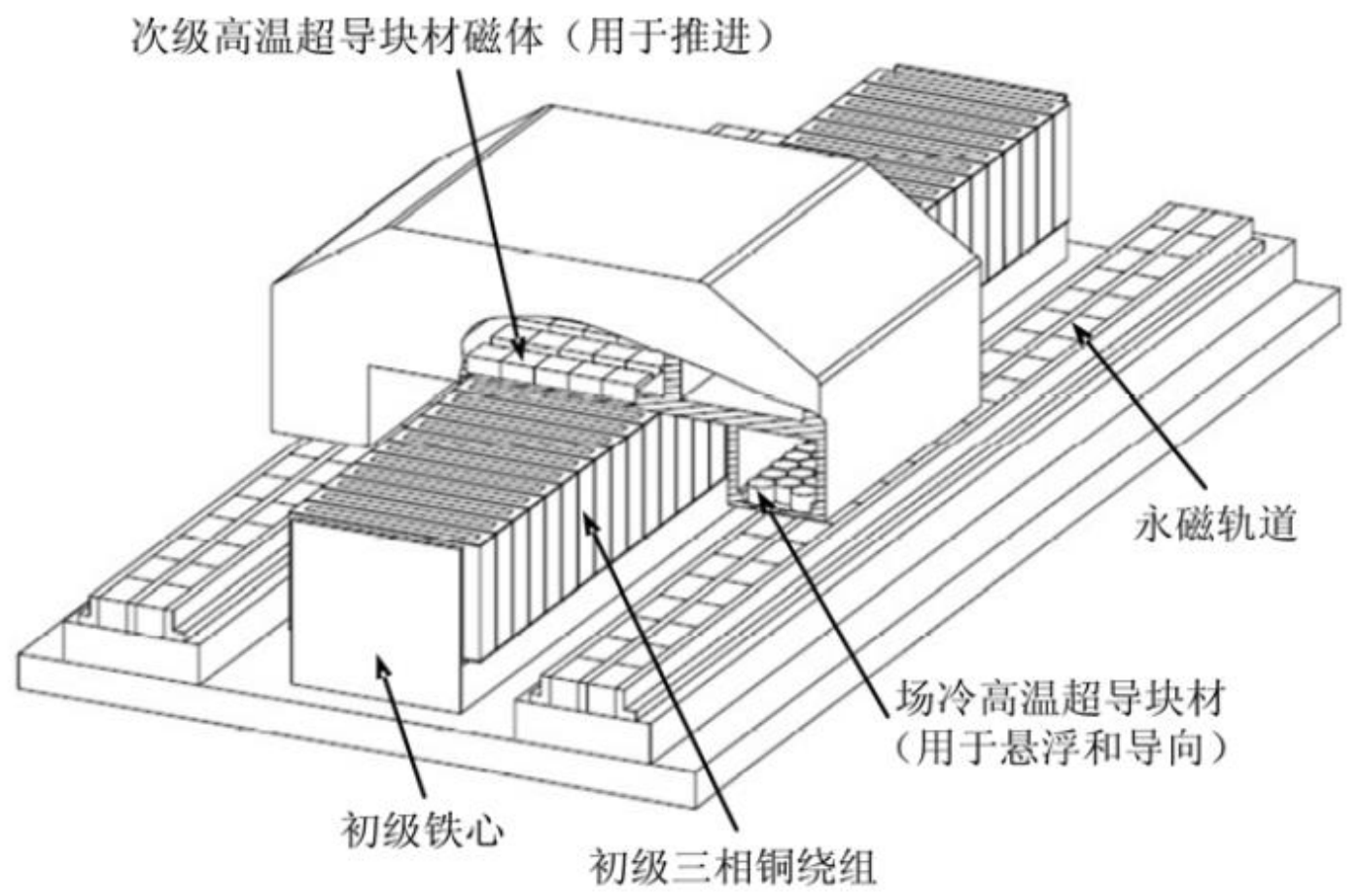

Fig. 23. Comprehensive HTS maglev train system

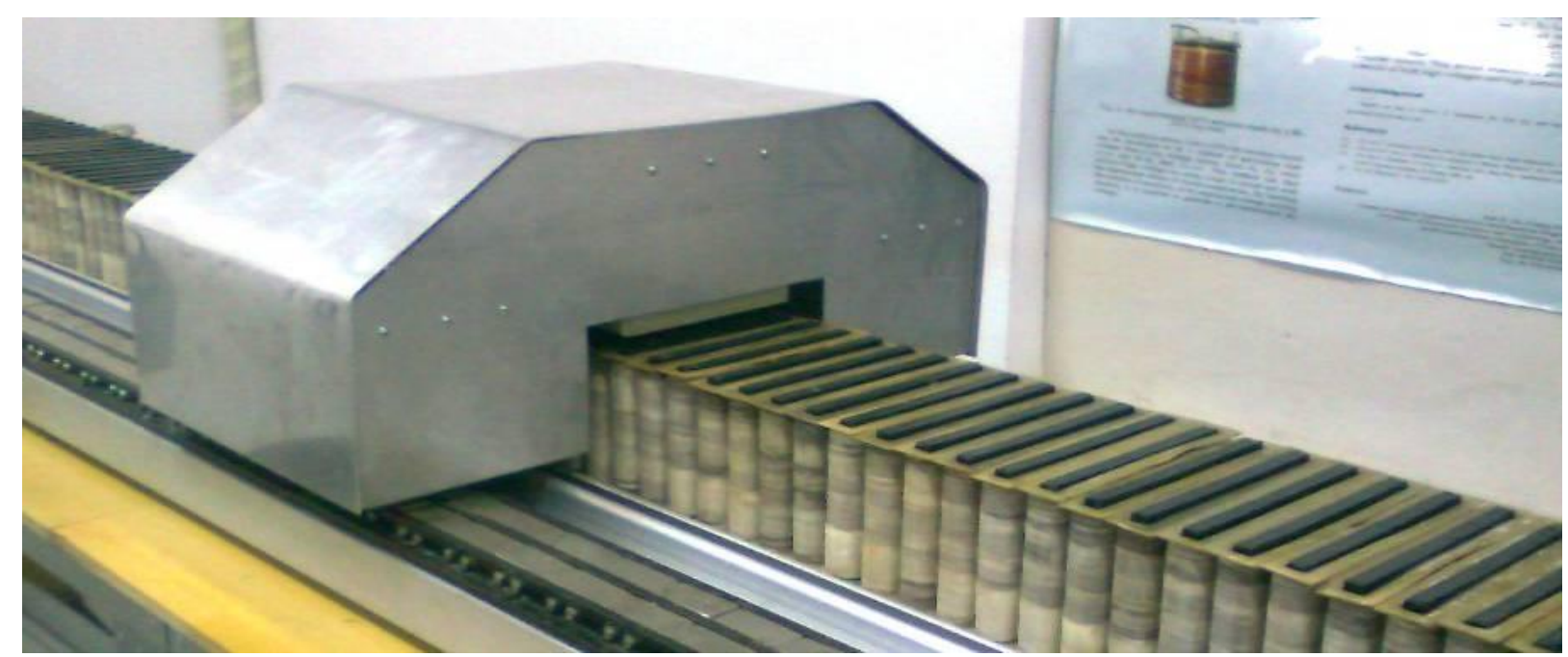

Fig. 24. Developed comprehensive HTS maglev train

Fig. 24 shows the develop prototype of the comprehensive HTS maglev train. The primary is $2.2 \mathrm{~m}$ long and $0.15 \mathrm{~m}$ wide. The slot pitch is $30 \mathrm{~mm}$; pole pitch is $45 \mathrm{~mm}$. the secondary is designed with modules. Each module has a Dewar vessel and 30 HTS bulks. 


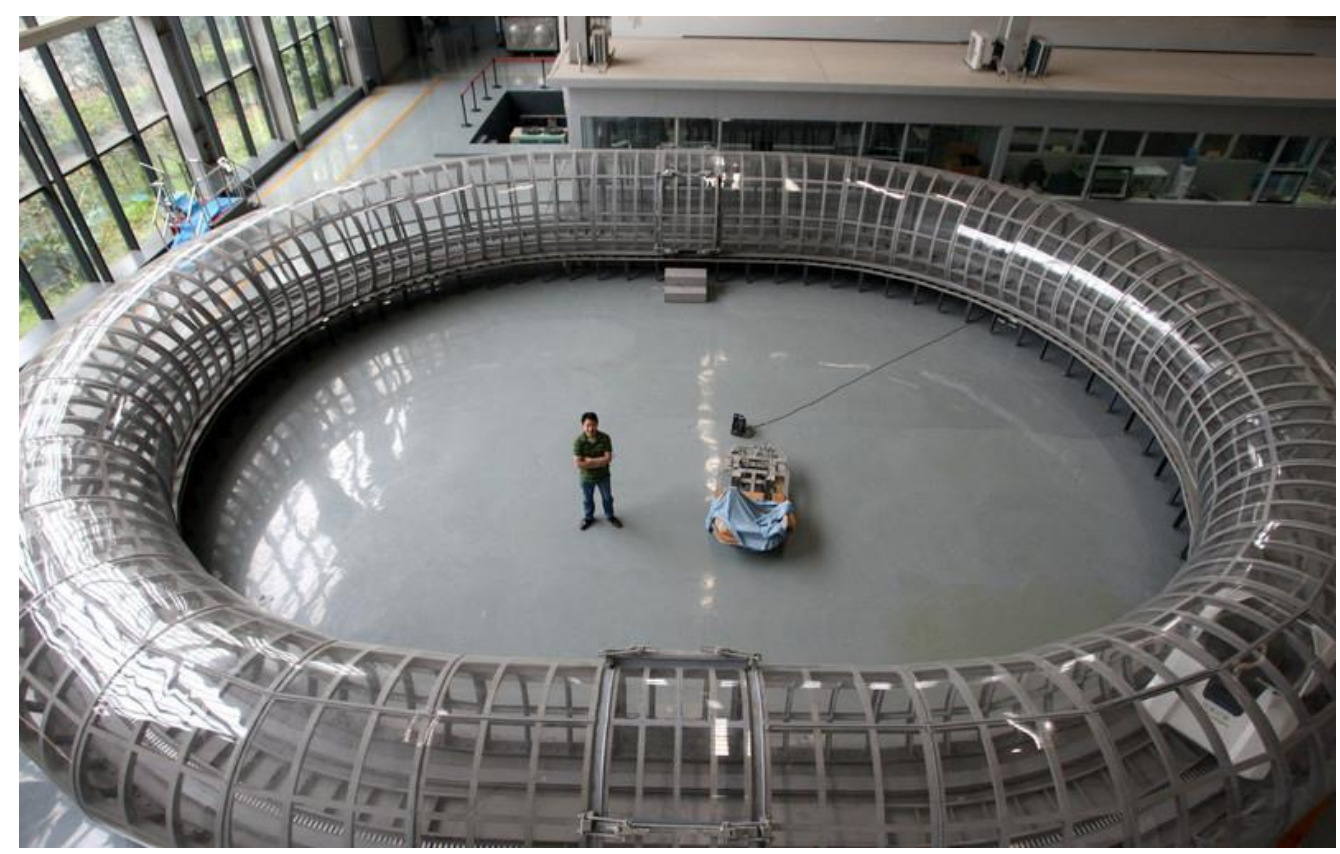

Fig. 25. Test facilities of the evacuated tube HTS maglev train

In Mar. 2013, the scholars in Southwest Jiaotong University developed the test facilities of the evaluated tube HTS maglev train (ETT). When ETT was operated, the pressure in the tube is only $1 / 10$ of the normal atmosphere pressure. Thus, the resistance of the air will be very small. The train will travel faster. Due to the dimension of the test facilities (the diameter is $6 \mathrm{~m}$ ), the prototype train only was tested with a speed of $50 \mathrm{~km} / \mathrm{h}$. A larger test facility is planning to be built for the high-speed test works.

\section{$B \quad H T S$ linear metro}

Due to the expensive construction cost of the HTS maglev trains, a few researchers has switched their attentions on the HTS linear metro, which is much cheaper than the HTS maglev trains. Prof. Jin Fang in Beijing Jiaotong University developed the first HTS linear induction motor aimed to linear metro, as shown in Fig. 26. The primary consists of Dewar, core, and the HTS coils, whereas the secondary is composed of an aluminum plate and an iron plate. The synchronous speed is $3.5 \mathrm{~m} / \mathrm{s}$, the peak thrust is larger than $1000 \mathrm{~N}$. 


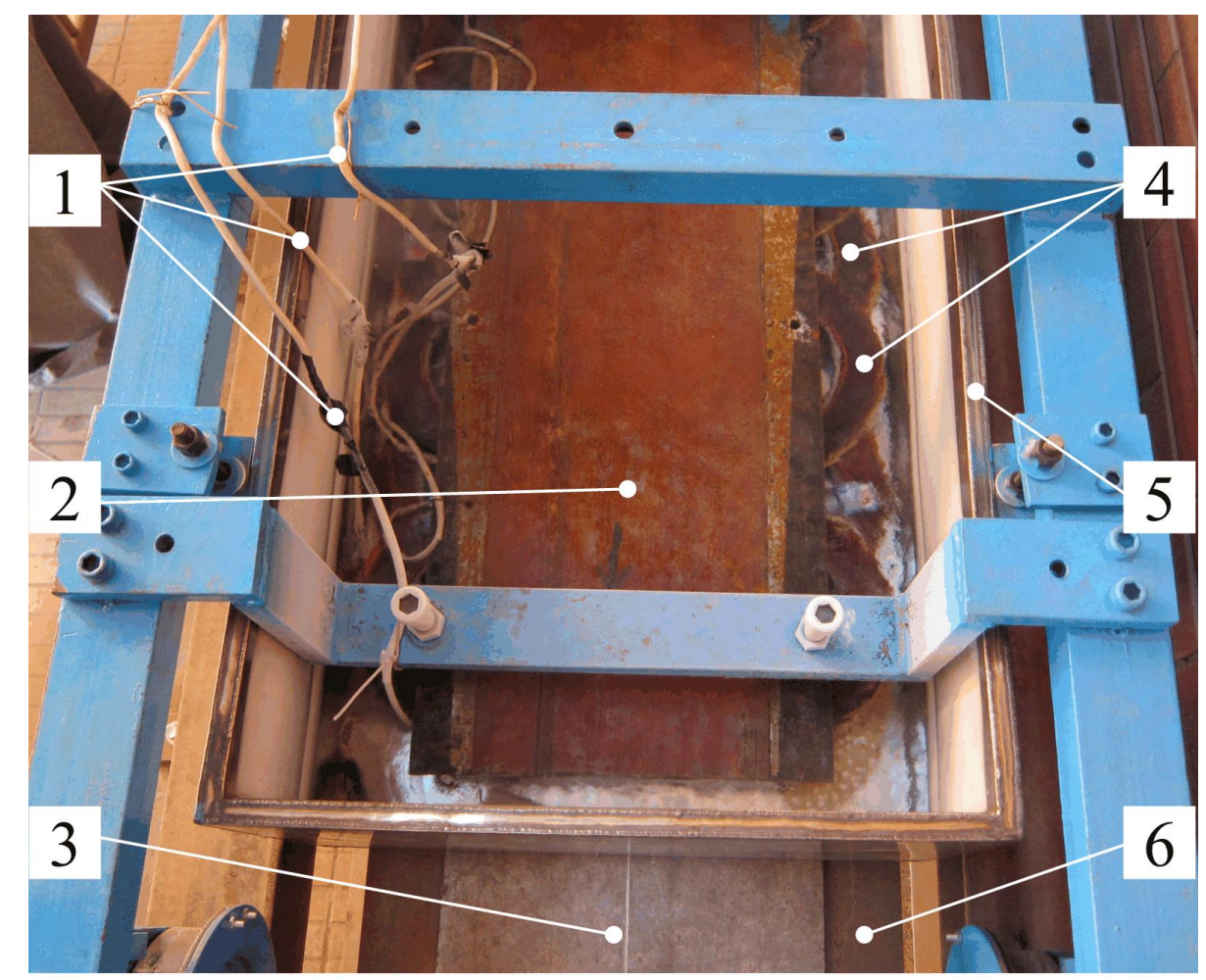

Fig. 26. HTS linear induction motor aimed to linear metro (1-power supply, 2-core, 3aluminum plate, 4-HTS coils, 5-Dewar, 6-iron plate)

The HTS linear induction motor was tested in a $20 \mathrm{~m}$ rail. The measured results are shown in Fig. 27. When the operated frequency is set to $4 \mathrm{~Hz}$, the speed is $3.35 \mathrm{~m} / \mathrm{s}$. The average thrust is $934 \mathrm{~N}$; and peak thrust is larger than $1200 \mathrm{~N}$.
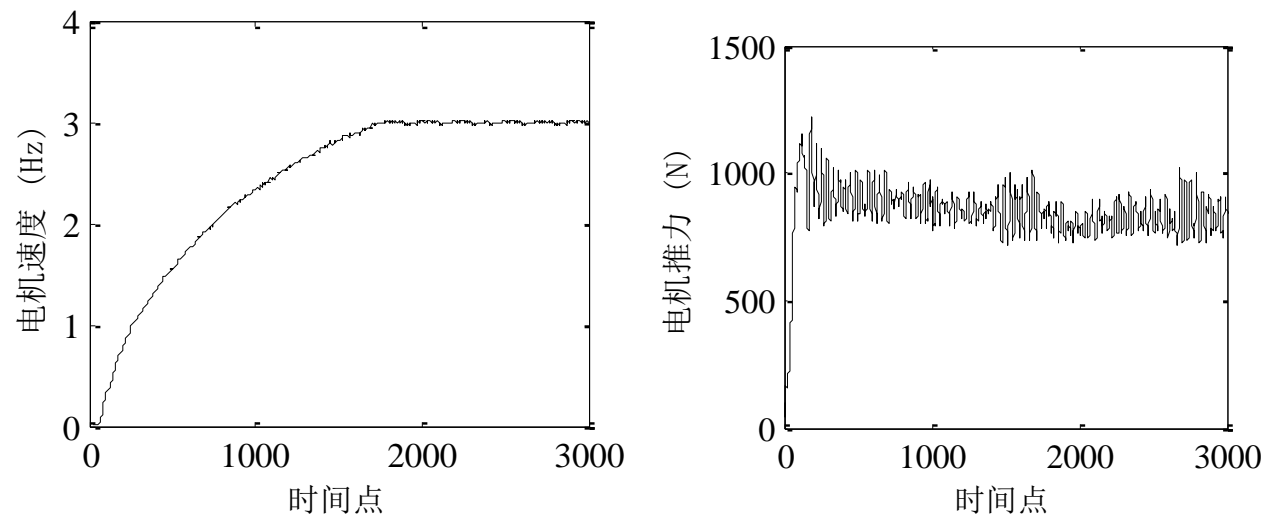

Fig. 27. Measured results of HTS linear induction motor used for linear metro 


\section{Conclusions}

Although China has gain a great progress in the construction and research of the linear rail transit system, it is still a great gap with the foreign advanced technology. As the key technology in $21^{\text {st }}$ century, China addresses great importance to the high-temperature technology, especially the applications of the HTS technology to the industries. By learning the advanced technology and developing by itself, China will play an important role in the linear rail transit system and the application of the HTS technology.

\section{References}

1. Li D., Li W., Fang J., \& Zhang X. IEEE Trans. Appl. Supercond., 2014 vol. 24, pp. 1-10.

2. Musolino A., Rizzo R. \& Tripodi E. IEEE. Trans. Plasma Sci., 2013, vol. 41, pp. 1193-1200.

3. Jin J., Zheng L. H., Guo Y. G., Zhu J. G., Grantham C., Sorrell C. C. \& Xu W. IEEE Trans. Appl. Supercond., 2012, vol. 22, p. 5202617-5202617.

4. Zhang Y., Zhang M., Ma W., Xu J., Lu J. \& Sun Z. IEEE Trans. Energy Convers., 2012, vol. 27, pp. 572-579.

5. Huang X., Liu J., Zhang C. \& Li L. IEEE. Trans. Plasma Sci., 2013, vol. 41, pp. 1182-1187.

6. Li L., Pan D. \& Huang X. IEEE. Trans. Plasma Sci., 2013, vol. 41, pp. 1188-1192.

7. Gieras J. F., Mews J. \& Splawski P. IEEE Trans. Ind. Appl., 2012, vol. 48, pp. 106-116.

8. Li D., Li W., Fang J., Zhang X. \& Cao J. IEEE Transactions on, 2014, vol. 50, pp. 1-9.

9. Park C., Lee H. \& Lee J. J. Electr. Eng. Technol., 2012 vol. 7, pp. 200-206.

10. Higuchi T., Nonaka S. \& Ando M. Electr. Eng. Jpn., 2001, vol. 137, pp. 36-43.

11. Lee H., Lee S., Park C., Lee J.\& Park H. International Journal of Railway, 2008, vol. 1, pp. 6-11.

12. Thornton R., Thompson M. T., Perreault B. M. \& Jiarong F. Proc. IEEE, 2009, vol. 97, pp. 1754-1757.

13. Wang J., Wang S., Zeng Y., Huang H., Luo F., Xu Z., Tang Q., Lin G., Zhang C. \& Ren Z. Physica C., 2002, vol. 378, pp. 809-814.

14. Yang W. J., Wen Z., Duan Y., Chen X. D., Qiu M., Liu Y. \& Lin L. Z. Applied Superconductivity, IEEE Transactions on, 2006, vol. 16, pp. 1108-1111. 
15. Wang S., Wang J., Wang X., Ren Z., Zeng Y., Deng C., Jiang H., Zhu M., Lin G. \& Xu Z. Applied Superconductivity, IEEE Transactions on, 2003, vol. 13, pp. 2134-2137.

16. Jiasu W., Suyu W., Jun Z., Fei Y., Guangtong M., Lu L., Jing L. \& Wei L. Applied Superconductivity, IEEE Transactions on, 2011, vol. 21, pp. 1551-1555.

17. Zigang D., Jiasu W., Jun Z., Hua J., Jing L., Wei L., Ya Z. \& Suyu W. Applied Superconductivity, IEEE Transactions on, 2009, vol. 19, pp. 2137-2141.

18. Jiasu W., Suyu W. \& Jun Z. Applied Superconductivity, IEEE Transactions on, 2009, vol. 19, pp. 2142-2147.

19. Kuwano K., Igarashi M., Kusada S., Nemoto K., Okutomi T., Hirano S., Tominaga T., Terai M., Kuriyama T., Tasaki K., Tosaka T., Marukawa K., Hanai S., Yamashita T., Yanase Y., Nakao H. \& Yamaji M. Applied Superconductivity, 2007, IEEE Transactions on, vol. 17, pp. 21252128.

20. Yang W. J., Wen Z., Duan Y., Chen X. D., Qiu M., Liu Y. \& Lin L. Z. Applied Superconductivity, IEEE Transactions on, 2006, vol. 16, pp. 1108-1111.

21. Suyu W., Jiasu W., Xingzhi W., Zhongyou R., Youwen Z., Changyan D., He J., Min Z., Guobin L., Zhipei X., Degui Z. \& Honghai S. Applied Superconductivity, IEEE Transactions on, 2003, vol. 13, pp. 21342137.

22. Mirsalim M., Doroudi A. \& Moghani J. S. IEEE Trans. Magn., 2002, vol. 38, pp. 1365-1370.

23. Lee B. Journal of Electrical Engineering \& Technology, 2011, vol. 6, pp. 81-85.

24. Muramatsu R., Sadakata S., Tsuda M. \& Ishiyama A. Applied Superconductivity, IEEE Transactions on, 2001, vol. 11, pp. 1976-1979.

25. Sadakata S., Ueda H., Tsuda M. \& Ishiyama A. Applied Superconductivity, IEEE Transactions on, 2002, vol. 12, pp. 824-827.

26. Takahashi A., Ueda H. \& Ishiyama A. Applied Superconductivity, IEEE Transactions on, 2003, vol. 13, pp. 2251-2254.

27. Sato A., Ueda H. \& Ishiyama A. Applied Superconductivity, IEEE Transactions on, 2005, vol. 15, pp. 2234-2237.

28. Yoshida K. \& Matsumoto H. Physica C., 2002, vol. 378, pp. 833-837.

29. Yoshida K. \& Matsumoto H. Physica C., 2003, vol. 392, pp. 690-695.

30. Yoshida K. \& Matsumoto H. IEEE Trans. Magn. , 2004, vol. 40, pp. 615-618. 
31. Yoshida K., Matsumoto H. \& Eguchi M. Physica C, 2005, vol. 426, pp. 839-847.

32. Kellers J., Behrens P., Buhrer C., Muller J. \& Wiezoreck J. IEEE Trans. Appl. Supercond., 2007, vol. 17, pp. 2121-2124.

33. Pina J. M., Neves M. V., McCulloch M. D. \& Rodrigues A. L. Design of a linear synchronous motor with high temperature superconductor materials in the armature and in the field excitation system. 2006, 804 p.

34. Pina J., Pereira P., Valtchev S., Gonçalves A., Neves M. V., Alvarez A. \& Rodrigues L. A test rig for thrust force measurements of an all HTS linear synchronous motor. 2008, 12220 p.

35. Pina J. M., Neves M. V. \& Rodrigues A. L. Case Study in the Design of HTS Machines: an All Superconducting Linear Synchronous Motor. 2007, pp. 185-190.

\section{Information about authors:}

Weili LI, Doctor in Engineering, Professor in School of Electrical Engineering, Beijing Jiaotong University, E-mail: wlli@ bjtu.edu.cn

Dong LI, Doctor in Engineering, Lecturer in School of Electrical Engineering, Beijing Jiaotong University, E-mail: lidong223@bjtu.edu.cn

Xiaochen ZHANG, Doctor in Engineering, Lecturer in School of Electrical Engineering, Beijing Jiaotong University, E-mail: xchzhang@bjtu.edu.cn

Junci CAO, Doctor in Engineering, Associate professor in School of Electrical Engineering, Beijing Jiaotong University, E-mail: jccao@bjtu.edu.cn

(C) WEILI LI, DONG LI, XIAOCHEN ZHANG, JUNCI CAO, 2016 